Al1102 69772ᄅ

NATL INST OF STANDARDS \& TECH R.I.C

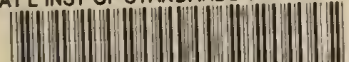

A11102697722

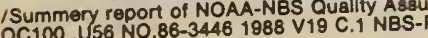

\title{
Summary Report of NOAA-NBS Quality Assurance Workshop December 1985, 1986
}

John K. Tavlor, Editor

U.S. DEPARTMENT OF COMMERCE

National Bureau of Standards

National Measurement Laboratory

Center for Analytical Chemistry

Gathersburg, MD 20899

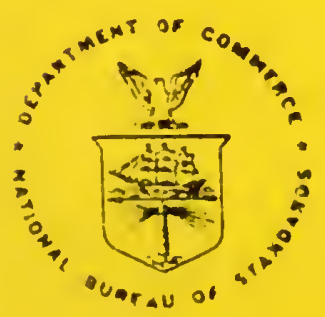

U.S. DEPARTMENT OF COMMERCE

$-O C$ JREAU OF STANOARDS

100

.1156

\#86-3446

1986 



\section{SUMMARY REPORT OF NOAA-NBS} QUALITY ASSURANCE WORKSHOP DECEMBER 1985, 1986

John K. Taylor, Editor

U.S. DEPARTMENT OF COMMERCE

National Bureau of Standards

National Measurement Laboratory

Center for Analytical Chemistry

Gaithersburg, MD 20899

August 1986

U.S. DEPARTMENT OF COMMERCE, Malcolm Baldrige, Secretary NATIONAL BUREAU OF STANDARDS. Ernest Ambler, Director 

TABLE OF CONTENTS

Page

Introduction

The Role of Specimen Banking in the NOAA Status and Trends

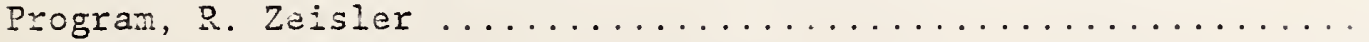

Trace Analysis and Quality Assurance for Extractable Organics

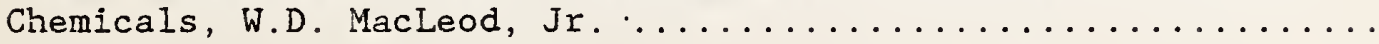

Intercomparison for Trace Metals in Marine Sediments,

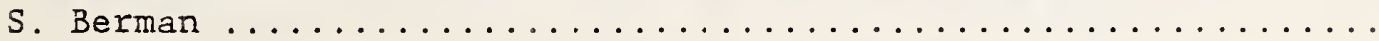

A Statistical Review of Inter-Laboratory Comparison Daca,

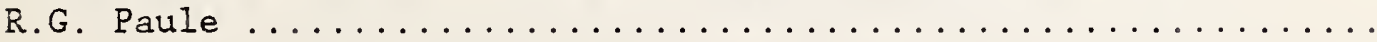

Organic Methods Workshop Summary, S.A. Wise, M.M. Schantz, and W.E. May

Inorganic Methods Workshop Summary, T.C. Rains ............ 17

Long-Term Goals, J.K. Taylor ....................... 19

Reference Materials for Marine Analysis, W.E. May ........... 22

Appendix A - Workshop Agenda ..................... 25

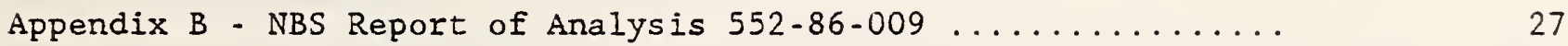

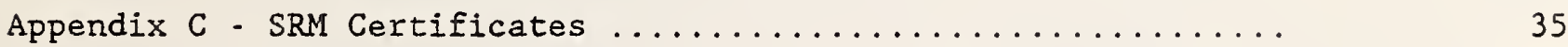

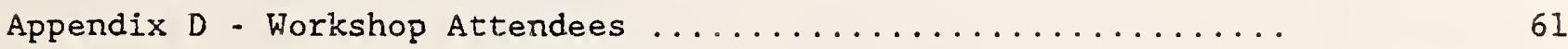





\author{
Summary Report \\ Quality Assurance Workshop \\ Co-Sponsored by \\ NOAA - NBS \\ National Bureau of Standards \\ Gaithersburg, MD 20899 \\ December 5-6, 1985 \\ Abstract
}

This report sumarizes the proceedings of a methods development, quality assurance workshop held at the National Bureau of Standards, December 5-6, 1985, as part of NOAA's continuing effort to improve the quality of marine monitoring data. The workshop consisted of a series of contributed papers and group discussions of the resuits of collaborative measurements of a group of test samples. Summaries of the papers and the group discussions are included in this report.

\title{
INTRODUCTION
}

The quality of marine monitoring data is of mutual concern of the Ocean Assessment Division (OAD) of NOAA and to the laboratories that furnish much of this on a contract basis. Accordingly, NOAA/OAD has entered into an agreement with the National Bureau of Standards (NBS) to organize and conduct a series of method development/quality assurance workshops to be held on a regular basis. The several purposes of these workshops are: (1) to promote intercomparability of data from the various methods used by OAD contractors; (2) to identify and seek solutions to problems with various methods and techniques; (3) to discuss quality assurance practices, their implementation, and their value; (4) to review results from past interlaboratory comparison exercises and plan future ones; and (5) to improve the application of statistics to marine environmental quality measurements.

This report summarizes the proceedings of the first workshop, held at NBS, Gaithersburg Maryland during December 5-6, 1985. The Agenda, reproduced in Appendix A, consisted of contributed papers and two concurrent workshops on Inorganic Methods and Organic Methods, respectively. The latter were devoted to presentations of the results of collaborative measurements of special test samples and in-depth discussions by the attendees of their experiences gained in analyzing them. Such feed-back is considered to be essential for both improving the quality of test materials and for identifying and solving measurement problems. The texts of the contributed papers and summaries of the workshops discussions are contained in the following sections of this report.

\section{Conclusion}

The response of the attendees of this first workshop has encouraged OAD/NOAA to sponsor a second workshop to be held at the Northwest and Alaska Fisheries Center. Seattle Washington, on December 3-4, 1986. A second series of test samples will have been prepared, distributed, and analyzed by that time, and the results subjected to statistical evaluation. The discussion of these results will be a major part of the 1986 workshop. 


\section{R. Zeisler}

National Bureau of Standards

A list of all presently suspected environmental hazardous substances would contain thousands of chemicals produced in significant quantities around the world; and industry is adding new compounds to that list every year. In addition, naturally occurring toxic elements and compounds would be included which are reentering the environment via industrial processes at rates much greater than their natural degradation or removal from the biosphere. To monitor their ecotoxic behavior and discernible effects would require the analysis of environmental samples for all the hazardous chemicals and their metabolites or decomposition products. However, this is all but impossible. Hence, monitoring programs generally focus on the measurement of specific chemicals that are recognized as hazardous or that may be of particular interest to a specific study, thus exploiting only a fraction of the information content of a particular sample at the time of the investigation.

To complement the necessarily limited real-time monitoring activities, the concept of environmental specimen banking (ESB) has been recognized as an important part of systematic environmental monitoring ( $1-3$ ). ESB is providing comprehensive records of the current state of ecosystems without the need for immediate analysis and without the danger of consumption of the sample before the desirable information has been extracted. The banked specimens will allow retrospective analysis of yet unknown pollutants as well as for the use of new or improved techniques for the determination of presently undetectable chemicals. Systematic and repetitive anaiyses over time of comparable ESB samples will yield information on the present distribution and its trends for selected key chemicals which can be related to a known baseline, i.e., the banked specimens.

Several pilot ESB programs were established approximately a decade ago and have serred as nuclei for the development of appropriate approaches on ESB (4) In the U.S., the Environmental Protection Agency (EPA) and the National Bureau of Standards (NBS) have been involved in a pilot study to evaluate the feasibility of ESB as an important part of environmental monitoring. The core objective of the EPA/NBS Pilot National Environmental Specimen Bank (NESB) was the development of a comprehensive analytical approach for ESB. This has been demonstrated in the NESB on one specimen type, namely human livers (5). The experiences gained, the technologies developed, and the analytical approaches designed in the NESB will now benefit new programs that are presently added to the initial effort. Although the inclusion of monitor specimens from the marine environment was planned in the conception of the NESB, the inclusion of samples from the National Status and Trends (NS\&I) Program will be the Eirst large scale implementation of ESB in the U.S. for the marine environment.

The NS\&T Program will be supported through the development of verifled protocols for taking, handling, preparing and storing of various indicator specimens collected in the estuarine and coastal waters. These protocols are 
designed to ensure validity of the banked samples in terms of non-altered chemical composition from the time the sample is taken to the time of analysis. Approximately 208 of the sites will be selected in each year for banking of the respective specimens, thus providing a complete archive of all sites within five years. A selected number of key specimens will be analyzed with methodology developed in the NESB to provide real-time benchmark data for reference and comparison with other analysts and analytical methods.

\section{References}

1. Berlin, A., Wolff, A.H.; Hasegawa, Y., Eds. "The Use of Biological Specimens for the Assessment of Human Exposure to Environmental Pollutants"; Martinus Nijhoff Publishers: The Hague, the Netherlands, (1979).

2. Luepke, N. -P., Ed. "Monitoring Environmental Materials and Specimen Banking"; Martinus Nijhoff Publishers: The Hague, the Netherlands, (1979).

3. Lewis, R.A.; Stein, N.; Lewis, C.W., Eds. "Environmental Specimen Banking and Monitoring as Related to Banking"; Martinus Nijhoff Publishers: The Hague, the Netherlands, (1984).

4. Wise, S.A. and Zeisler, R., Eds., International Review of Environmental Specimen Banking, NBS Spec. Pub1. 706, U.S. Government Printing Office, Washington, DC, (1985).

5. Wise, S.A., Zeisler, R., "The Pilot Environmental Specimen Bank Program" Environ. Sci. Techno1., 18, 302A (1984). 


\section{Trace Analvses and Quality Assurance for Extractable Organics Chemicals}

William D. MacLeod, Jr. Northwest and Alaska Fisheries Center

The marine environment for decades has been a dumping ground directly or indirectly for a host of chemicals. The National Oceanic and Atmospheric Administration (NOAA) has long been interested in the extent and impact of this contamination on our Nation's living marine resources. Last year, NOAA launched a nationwide study of coastal contamination with its "National status and Trends Program for Marine Environmental Quality" (NS\&T). Central to this multi-million dollar program is the need to known which key chemicals contaminate our marine environment and what are their trends. It is most important that this knowledge be of such quality that it can be used with statistical confidence in helping to understand the nature and extent of chemical pollution both locally and nationwide. This section deals with analyses and quality assurance (QA) for the extractable toxic organic chemicals under the NS\&T Program.

For many reasons, analytical procedures for extractable toxic organics need to be sensitive, down to parts-per-billion (ppb) and sometimes lower. At the same time, these procedures also must meet standards of reliability. Generally speaking, such procedures must be performed with painstaking care by skilied and experienced laboratory personnel on sophisticated analytical instzuments. Often acceptable reliability (Horwitz, et al. 1980) may be attained at the desired sensitivity only with the best of efforts. Unfcrtunately, in the community of marine environmental research, analyses for trace organics have not always been practiced to uniform professional analytical standards. To address such deficiencies, two years ago the American Chemical Society issued its "Principles of Environmental Analyses" (Keith, et al. 1983), giving special emphasis to QA. Related to this action, last year NOAA launched a QA program for its NS\&T Program.

At NOAA's National Analytical Facility (NAF), we have been involved in the analyses and QA for extractable organics. Our laboratory manual (Macleod, et al. 1985) provides NS\&T with detailed and standardized analytical procedures for the extractable organics. This manual is now in its second edition as NOAA Tech. Memo. NMFS F/NWC-92, which supersedes the earlier version (MacLeod, et al. 1984). We also prepare the GC calibrating and internal standards for the extractable organic chemical contaminants, an the reference sediments and tissues used to monitor laboratory performance.

The procedures described in the manual are lengthy and detailed for a number of reasons. This is largely due to the complex mixtures of extractable organic compounds that marine environmental samples often contain. To be effective, an extraction and cleanup procedure must separate numerous naturally occurring compounds from the toxic organic analytes of interest. Figure 1 demonstrates difficulties that can be encountered in an analysis of a marine sediment. The upper portion is the gas chromatogram of the aromatic hydrocar. 
bon fraction after what was once regarded as adequate cleanup by liquid chromatography. In the figure, each upscale deflection is the result of ore or more organic compounds reaching the instrument's detector and giving a measurable response at a given point in time. Obviously, if more than one compound enters the detector at the same time, analyte quantitation may be seriously compromised.

To remove the interfering compounds, we developed an additional cleanup step (Ramos and Pronaska, 1981) which reduces the complexity of the uppe: chromatogram to the more tractable mixture shown in the lower chromatogram. The analytes of interest are denoted by numerals and listed in the legend. While some extraneous compounds remain in the lower chromatogram, few of them now interfere with the measurement of the analytes of interest. Other techniques described in the manual are depicted in the flow chart shown in Figure 2. Most of these are relatively well known and need no further discussion here, except to point out that they are essential, which of course makes the overall procedure lengthy.

In any discussion of quality assurance and methodology, consideration should be given to what can be accomplished when the proper analytical principles are observed irrespective of the particular analytical method followed. Figure 3 shows a comparison of results from an earlier NOAA sponsored study (Macleod, et al. 1982). Participating laboratories weze free to use their own procedures. The upper portion is a graph of the aromatic hydrocarbons found by another marine research laboratory. The lower portion is a graph of our own results on the same reference material. In this instance, the results were remarkably similar, even though eaci laboratory used a different approach. That's the good news. The bad news is that this is the cnly example of its kind we have encountered in more than five years of interlaboratory comparisons with more than thirty laboratories.

We felt that more rigorous control of the many variables was needed. Quality assurance under NOAA's NS\&T Program provided us with an opportunity to test such an approach. It began last year with the "National Benthic Surveillance Project, " a nationwide component of NS\&T conducted by the National Marine Fisheries Service (NMFS). Two other NMFS laboratories are involved, one under the Southeast Fisheries Center in Charleston, South Carolina, and the other under the Northeast Fisheries Center in Gloucester, Massachusetts. Chemists from these NMFS labs expressed interest in employing the analytical procedures we had found useful over the years. For our part, we undertook to describe these procedures in the detailed format now published (Macleod, et al. 1985) and to manage interlaboratory comparisons. Thus, the NMFS labs went forward with a common approach to the analyses for extractable toxic organics.

Specifically, the NMFS labs used the following:

- The same detailed methods manual

- The same cherked and approved reagents

- The same calibration standard solutions

- The same internal standard solutions

- The same reference materials

We believe that the establishment of such a common, validated approach 
nationwide is a significant advance in the analysis of extractable toxic organics in the marine environment. In these analyses, the following QA measures are specific in the lab manual.

- Frequent Calibration Check of GC Performance

- Internal Standards for: (a) Extraction, (b) GC

- Blank Analyses

- Spiked Blank Analyses ("Reagent Spike")

- Blind Duplicate Analyses

- Reference Materials Analyses

We are now in the process of comparing results from the NS\&T laboratories and determining whether environmental analytical data for extractable organics can be compared nationwide on a common basis. The bottom Iine for QA is the comparison of analyses of reference materials between various labs. Tables 1 through 3 contain analytical results from the NMFS laboratories on the Duwamish III reference sediment. There hasn't been time to conduct a thorougi statis. tical examination of these cata, but preliminary inspection of the data suggests that they may be more consistent than those found in our earlier study (Macleod, et al. 1982) involving analyzes of Duwamish I and II reference sediments. Should this prove to be statistically true, it would represent an accomplishment, in view of the divergent prior experience in these kinds of analyses by the NMFS labs.

\section{References}

Horwitz, W., L.R. Kamps, and K.W. Boyer, 1980. Quality Assurance in the Analysis of Foods for Trace Constituents, J. Assoc. Off. Anal. Chem. 63, $1344-1354$.

Keith, L.H., W. Crummet, J. Deegan, Jr., R.A. Libby, J.K. Taylor, and G. Wentler, Principles of Environmental Analyses, Anal. Chem. 55, 2210-2218 (1983).

Macleod, W.D., Jr., P.G. Prohaska, D.D. Gennero, and D.J. Brown, 1982. Interlaboratory Comparisons of Selected Trace Hydrocarbons from Marine Sediments, Anal. Chem. 54, 386-392 (1982).

Macleod, W.D., Jr., D.W. Brown, A.J. Friedman, O. Maynes, and R.W. Pearce, Standard Analytical Procedures of the NOAA National Analytical Facility. 1984-1985; Extractable Toxic Organic Compounds, NOAA Technical Memorandum NMFS F/NWC-64, 110pp. (1984).

MacLeod, W.D., Jr., D.W. Brown, A.J. Friedman, D.G. Burrows, O. Maynes, and R.W. Pearce, C.A. Wigren, and R.A. Bogar, Standard Analytical Procedures of the NOAt National Analytical Facility, 1984-1985: Extractable Tox1c Organic Compounds, Second Edition, NOAA Technical Memorandum MMS F/NiC. $92,121 \mathrm{pp}$.

Ramos, L.S. and P.G. Prohaska, 1981, Sephadex LH-20 Chromatography of Extraces of Marine Sediment and Biological Samples for the Isolation of Polynuclear Aromatic Hydrocarbons, J. Chromatog. 211, 284-289. 
Table 1. Mean concentrations $(n=3)$ in $\mathrm{ng} / \mathrm{g}$ dry weight of selected aromatic hydrocarbons found in reference sedinent: Diwamish III. Relative standard deviations expressed as a percent of mean are sincwn in parentheses. NAF = ilational Analytical Facility, $\mathrm{NE}=$ Northeast Fisheries Center, $\mathrm{SE}=$ Southeast Fisheries Center

Compourd

napthahalene

2-methylnaphthalene

1-methylnaphthaiene

biohery 1

2,6-dimethy Inaphthalere

acenaphchere

Eluorene

phenantirere

anthracene

1- Methy'phenanthrere

Eluoranthene

pyrene

benz [a] pyrene

chrysere

benzoie] pyrene

benzo [a] pyrcene

perylene

dibenz $[a, h]$ anthracene
NAF Chen.

$\begin{array}{ccccc}320(11) & 320(15) & 420(18) & 250(21) & 330(11) \\ 160(17) & 150(4) & 200(33) & 110(19) & 180(6) \\ 120(16) & 110(5) & 150(32) & 80(16) & 150(8) \\ 39(13) & 21(7) & 37(23) & 31(8) & 57(7) \\ 70(10) & 75(7) & 78(15) & 58(15) & 76(4) \\ 300(22) & 310(8) & 200(2) & 290(16) & 420(9) \\ 310(3) & 330(5) & 330(9) & 290(18) & 430(10) \\ 2300(8) & 2300(7) & 2400(5) & 2200(9) & 3200(6) \\ 510(3) & 590(9) & 550(2) & 550(16) & 730(2) \\ 220(11) & 220(7) & 220(5) & 410(52) & 320(10) \\ 3900(9) & 4000(6) & 3900(4) & 3700(4) & 5600(7) \\ 4100(5) & 4400(3) & 4200(4) & 3900(5) & 5300(6) \\ 1500(7) & 1900(8) & 1700(3) & 1400(5) & 2100(10) \\ 2600(7) & 3800(15) & 2700(4) & 2100(7) & 3600(6) \\ 1600(4) & 2000(8) & 1700(3) & 1400(5) & 2000(9) \\ 1800(3) & 2200(3) & 1800(3) & 1700(7) & 2700(6) \\ 510(2) & 640(5) & 550(5) & 460(8) & 710(5) \\ 310(4) & 470(11) & 280(2) & 310(5) & 430(7)\end{array}$

Table 2. Mean concentrations $(n=3)$ in $n g / g$ dry weight of selected chlorinated campounds found in reference seciment: Duramish III. Relative standard deviations expressed as a percent of mean are shown in parentheses. NAF = Vational Analytical Facility, NE = Northeast Fisheries Center, SE = Scutheast Fisheries Center

Compound NAF Chem. 1 NAF Chem. 2 NAF Chem. 3 NE SE

\begin{tabular}{|c|c|c|c|c|c|}
\hline heyachloroberzene & $* 0.4(36)$ & $\infty .9$ & $\infty 0.4(7)$ & $0.6(14)$ & $32(26)$ \\
\hline lindane (gamma-BHC) & $\infty .2$ & $\infty .6$ & $\infty .3$ & $\infty .6$ & 4 \\
\hline heptachlor & $<0.4$ & $\triangleleft$ & $\lessdot 0.5$ & $\bowtie .7$ & $<2$ \\
\hline aldrin & $<0.3$ & $\infty .7$ & $\infty .4$ & $\infty .6$ & $<$ \\
\hline heptachlorepoxide & $\infty .3$ & 4 & $\infty .5$ & $\infty .8$ & $<$ \\
\hline alpha-chlordane & $0.9(3)$ & $2(22)$ & $1(13)$ & $2(11)$ & $2(3)$ \\
\hline trans-nonachlor & $0.4(1)$ & $0.6(27)$ & $0.4(7)$ & $0.9(17)$ & 4 \\
\hline dieldrin & $\infty .3$ & $\triangleleft$ & $\infty .5$ & $\infty .7$ & $<$ \\
\hline mirex & $\infty .4$ & 4 & $\infty .6$ & $\infty .8$ & $<$ \\
\hline $0, p^{\prime}-\mathrm{DDE}$ & $<0.4$ & 4 & $\ll 0.6$ & 1 & 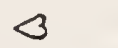 \\
\hline $\mathrm{D}, \mathrm{P}^{\prime}-\mathrm{DDE}$ & $7(11)$ & $9(16)$ & $7(4)$ & $10(37)$ & $9(6)$ \\
\hline $0, p^{\prime}-\mathrm{DDD}$ & $4(2)$ & $5(21)$ & $4(5)$ & $8(39)$ & $7(8)$ \\
\hline$P, P^{\prime}-$ CDD & $15(7)$ & $20(25)$ & $16(9)$ & $27(92)$ & $21(10)$ \\
\hline $0, p^{\prime}-D D T$ & $4(16)$ & $5(22)$ & $4(11)$ & $5(35)$ & 2 \\
\hline $\mathrm{p}, \mathrm{p}^{\prime}-\mathrm{DOT}$ & $\infty .5$ & $<$ & $\infty .7$ & $10(83)$ & $<$ \\
\hline
\end{tabular}

$x_{n-2}$ 
Table 3. Mean concentrations $(n=3)$ in $n g / g$ dry weight of polychlorinated biphenyl standards found in reference sediment: Duwamish III. Relative standard deviations expressed as a percent of mean are shown in parentheses. NAF = National Analytical Facility, NE = Northeast Fisheries Center, $\mathrm{SE}=$ Southeast Fisheries Center.

\section{Compound}

$2,4^{\prime}$-dichlorobiphenyl

2, 5,4' -trichlorobipherryl

$2,4^{\prime}, 2^{\prime}, 4^{\prime}$ - tetrachlorobipheny 1

$2,4,5,2^{\prime}, 5^{\prime}$-pentachlorobiphenyl

$2,4,5,2^{\prime}, 4^{\prime} 5^{\prime}$-hexachiorobipheny 1

$2,3,4,5,6,2^{\prime}, 5^{\prime}$-heptachlorobiphenyl

$2,3,4,5,2^{\prime}, 3^{\prime}, 4^{\prime}, 5^{\prime}$-octachlorobiphenyl

$2,3,4,5,6,2^{\prime}, 3^{\prime}, 4^{\prime}, 5^{\prime}$-nonachiorobipherryl
NAF Chen. 1 NAF Chem. 2 NAF Chem. 2

NE

SE

4
$23(7)$
$8(13)$
$70(20)$
$110(20)$
$\infty 0.4$
$8(27)$
$10(52)$

2

25 (2)

11 (14)

77 (9)

120 (30)

$\infty .1$

11 (16)

10 (17)
$<<8$

23 (10) 32 (19)

9 (7) 14 (11)

64 (14) 63 (3)

77 (10) 72 (4)

$5(30)<2$

17 (51) 9 (10)

17 (48) 7 (11) 


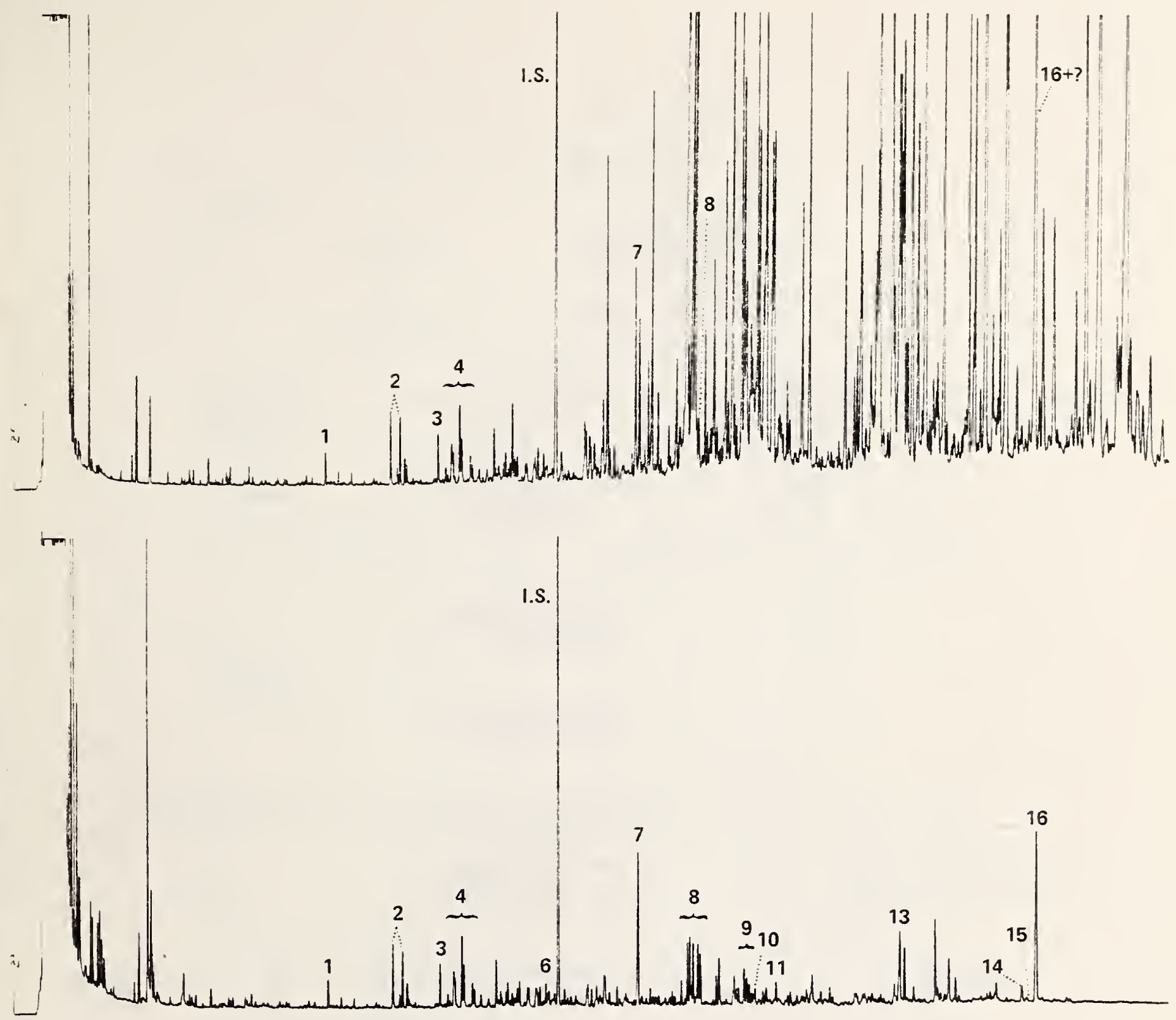

Time (min.)

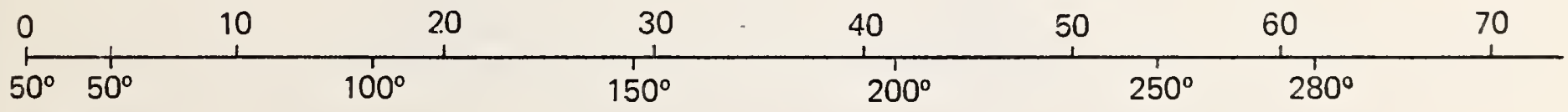

Temp. $\left({ }^{\circ} \mathrm{C}\right)$

Figure 1. Gas chromatogram of an intertidal sediment extract following chromatographic clean-up with (a) silica gel and (b) silica gel, followed by Sephadex LH-20 using cyclohexane-methanol-dichloromethane (Ramos \& Prohaska, 1981). Labelled peaks are: I.S. = internal standard; 1 - naphthalane; 2 - methylnaphthalenes; 3 biphenyl; 4 - dimethylnaphthalenes; 6 = fluorene; 7 - phenanthrene; 8 - methylphenanthrenes; 9 - dimethylphenanthrenes; 10 fluoranthene; 11 - pyrene; 13 - chrysene; 14 - benzo[e]pyrene; 15 - benzo[a]pyrene; 16 - perylene 


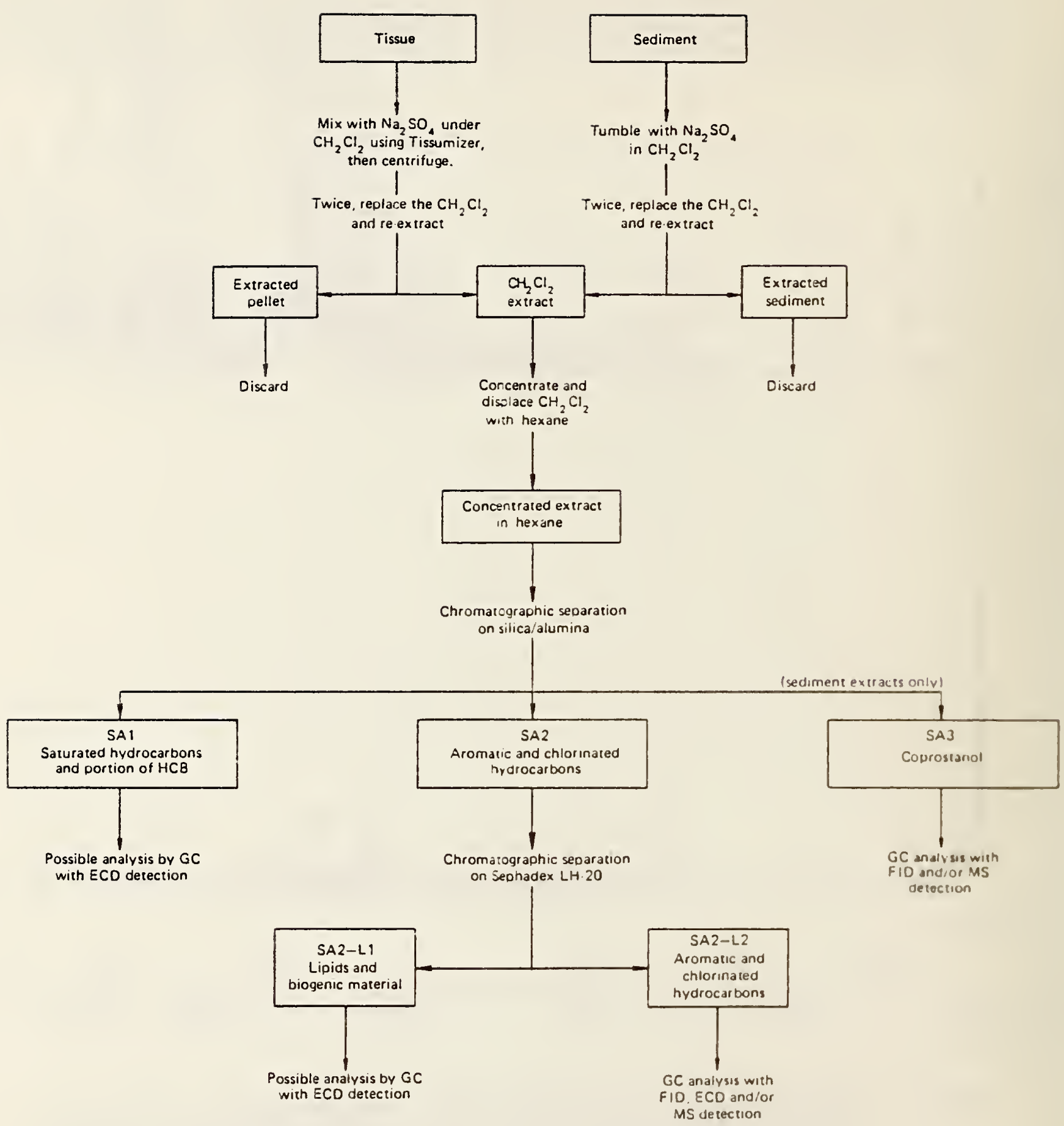

Figure 2. Summary of the Standard Analytical Procedures of NOAA's National Analytical Facility (Macleod, et al. 1985) 

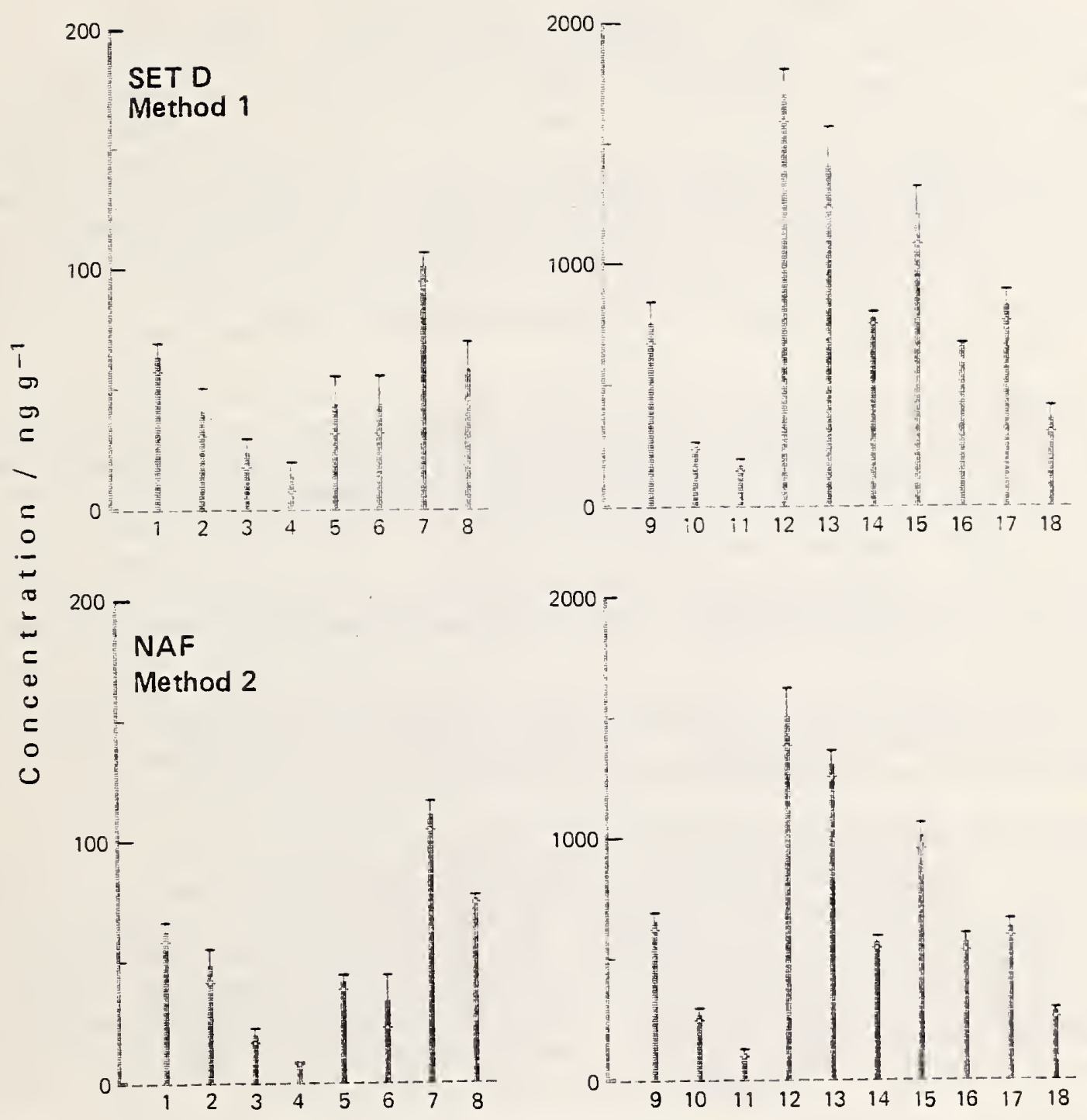

Figure 3. Bar graphs of selected aromatic compounds found in Duwamish II reference sediment (MacLeod, et al. 1982). Means ( $n=3$ ) and standard deviations shown for another marine science center (set D) and our laboratory (NAF). Compounds: 1 = naphthalene; 2 = 2 -methylnaphthalene; 3 - 1 -methylnapthalene; 4 - biphenyl; $5=$ 2,6-dimethylnaphthalene; 6 - 2,3,5-trimethylnaphthalene; $7=$ fluorene; 8 - dibenzothiophene; 9 = phenanthrene; 10 = anthracene; 11 - l-methylphenanthrene; 12 - fluoranthene; 13 - pyrene; 14 - benz[a] anthracene; 15 - chrysene; 16 - benzo[e]pyrene; 17 benzo[a]pyrene; 18 - perylene 


\section{Intercomparison for Trace Metals in Marine Sediments \\ S. Berman \\ National Research Council, Canada}

Four samples of marine sediments were prepared. These were essentially aluminum silicate materials typical of northeast coastal sediments. The sediments had been freeze dried, screened through $100 \mu \mathrm{M}$ screens, homogenized and bottled. Homogeneity tests in this laboratory involving the elements $\mathrm{Al}, \mathrm{Si}, \mathrm{Mn}, \mathrm{Fe}, \mathrm{Cu}, \mathrm{Zn}, \mathrm{Cd}, \mathrm{Hg}$ and $\mathrm{Pb}$ showed no significant differences between bottles and intrabottle precision between replicate samples to be no worse than the precision expected from the analytical procedures involved at the particular concentrations concerned.

The four samples consisted of two pairs, each with generally similar trace metal contents.

Samples were sent to the six participants in the late summer and early fall of 1985. The deadline, determined by the date of this workshop, and the lateness in receiving the names of the participants allowed only six to nine weeks for the determination of seventeen elements in the four sediments, each done on four replicate samples. It is hoped that future intercomparisons can be conducted on a somewhat more leisurely basis. To the credit of the participants, all submitted most of what was required from them.

A preliminary survey of the results (a final report will be issued by early spring, 1986) shows that, in general, the laboratories don't have problems with essential trace metals such as $\mathrm{Cu}, \mathrm{Zn}, \mathrm{Cd}, \mathrm{Hg}$ and $\mathrm{Pb}$.

There is concern regarding the analyses for the major components, $A 1$, $\mathrm{Si}$, and $\mathrm{Fe}$. The problems with these three may be in the sample decomposition or in matrix problems connected with their determination by flame atomic absorption spectrometry. The fact that a trace method is being used for a major concentration obviates the precision (and accuracy?) of traditional classical procedures. The one laboratory which used $x-r a y$ fluorescence spectrometry achieved acceptable values only for iron, indicating calibration problems.

There is some disappointment regarding results for manganese, nickel and arsenic. At the concentrations involved, a better precision was expected. The other six elements ( $\mathrm{Se}, \mathrm{Ag}, \mathrm{Sn}, \mathrm{Sb}, \mathrm{Ti}$ and $\mathrm{Bi}$ ) are present in very low concentrations. There is no doubt that some of the laboratories can analyze for these, but as there are no definitive values yet available there is not much to be said.

This laboratory is attempting to assign reliable values for most of the elements concerned in this study. The resulis will be reflected in the final report.

The results were discussed in detail in the inorganic analys is sessions. These discussions, I feel, were productive with much valuable deedback to the laboratories and the coordinator. 


\section{A Statistical Review of Interlaboratory Comparison Data \\ Robert C. Paule \\ National Bureau of Standards}

The following comments apply to the requirements for organizing an interlaboratory study, and for analyzing the data. The statistician and the coordinating scientist each bring specialized information to a successful study. In the planning stage, the scientist provides general information on what the field can do, and the statistician provides information on the types of answers that can be obtained.

Care should be taken in an interlaboratory study in the choice of materials to be sent to the laboratories. Homogeneous materials should be supplied at several levels for the analytes of interest, and they should have realistic interferences. The laboratories should be chosen to represent the laboratory population of interest.

Some of the answers obtainable from an interlaboratory study are: the average values for the test materials; the standard deviations for the average values; the standard deviation for a single laboratory measurement; and the within- and between-laboratory components of standard deviation. An interlaboratory study frequently gives a better understanding of the measurement process and indicates areas for improvement.

A number of increasingly complicated nested experimental designs were presented. The more complicated designs yield more information, but require that the laboratory measuremenes be in better control. Outlier values, in addition to distorting the averages, also present serious problems in the statistical analysis, and in subsequent probability statements. Outliers cause problems in the pooling of variances which are involved in the statistical analysis. For simple designs, reasonable compromises to the outlier problem sometimes can be made. Outliers, however, can be disastrous for complicated designs.

Interlaboratory studies that survey the state of the field normally should have simple designs since there is frequently a noticeable lack of measurement control. Several examples of survey type interlaboratory studies were presented.

Finally, the relative merits of graphical vs. quantitative statistical evaluations were discussed, and several examples were presented. 


\section{Organic Methods Workshop Summary}

\section{S.A. Wise, M.M. Schantz, and W.E. May \\ National Bureau of Standards}

The major focus of the Organic Methods Workshop was to review the results from the interlaboratory comparison study and to make recommendations for future quality assurance procedures for the NOAA National Status and Trends (NS\&T) Program. Prior to the workshop, samples of wet/frozen sediment and mussel tissue were prepared by the Northwest National Marine Fisheries Service (NMFS) and distributed for analysis to the NMFS laboratories, NOAA Mussel Watch contractors (i.e., Battelle New England Marine Laboratory, Science Applications International Co., and Texas A \& M University) and the National Bureau of Standards (NBS). These samples were to be analyzed for the determination of polycyclic aromatic hydrocarbons $(\mathrm{PAH})$, polychlorinated biphenyls (PCBs), and chlorinated pesticides. Results obtained on these samples by the various laboratories were discussed at the workshop. William MacLeod, Northwest NMFS laboratory, presented a detailed summary of the results obtained by his laboratory and the Northeast and Southeast NMFS laboratories. All three of these laboratories are using the analytical methods developed by the Northwest NMFS laboratory and published as a laboratory manual ( 1 ). The three Mussel Watch contractors were requested to also utilize these same procedures. Results for the sediment analyses from the Northwest NMFS lab showed good intralaboratory precision for analyses from three different analysts and reasonable agreement among the three NMFS laboratories. Unfortunately, the levels of the chlorinated pesticides in the samples were low and many of the reported values were at the detection limit. Preliminary results also were reported by the Mussel Watch contractors and by NBS for the sediment sample.

It was the general feeling of the contractors that they needed additional time to implement adequately the required NMFS procedures for the analyses. Also there was concern expressed by the Mussel Watch contractors regarding the need to implement the NMFS procedures exactly as detailed in the reference manual. A number of technical questions were discussed regarding the analytical procedures. Concern was expressed by several participants that the required use of the NMFS procedure by all of the laboratories involved in the program may result in precise data, but that NOAA would be unable to determine whether the results were accurate. There should be a means to validate the accuracy of this procedure. It was pointed out that the NBS values for the PAH, which were obtained by somewhat different methods, were in reasonable agreement with the data obtained by the NMFS procedures.

The NMFS procedure calls for the use of $3 \mathrm{~g}$ of tissue as the required sample size. It was suggested by the Mussel Watch contractors that this be increased to $10-20 \mathrm{~g}$. This larger sample size would allow greater sens1. tivity for the determination of the compounds of interest. This suggestion was adopted by NOAA.

Methods for the quantification of $\mathrm{PAH}$ and pesticide residues appear to be well-developed; however, there is need for improvement in the methods 
for quantification of PCBs. Questions regarding the basis to be used for the quantification of PCBs were raised, e.g., should total PCBs be quantified or individual PCB congeners; which congeners should be used to represent a specific group of PCBs with the same number of chlorine atoms? The individual congeners specified in the NMFS procedure for quantification were selected based on availability. The selection of more suitable congeners based on occurrence in the samples should be investigated.

There was an extensive discussion of the need for reference materials for marine tissue and sediment for use as control materials and in the validation of methods. IBS suggested that a series of different reference materials of varying complexity could be prepared, e.g., a sediment extract, cod liver oil to simulate a tissue extract, and frozen or dry sediment and tissue samples with either certified or "benchmark values". It was thought that the sediment extract might be unstable. A cod liver oil SRM will be available from NBS in late 1986 with certified values for selected pesticides and information values for PCBS and PAHs. Reference materials for the determination of PCDS and PAHs in sediment (air dried) are available from the National Research Council in Canada.

\section{Conciusions and Recommendations}

1. The laboratories involved in the NOAA NSET Program are reasonably comfortable with using the NMFS procedure if they have some latitude in the making of modifications, i.e., there needs to be a mechanism for implementing changes to the procedure and validation of those changes. This wotdd allow for improvement of analytical methocs throughout the duration of the NS\&I program rather than freezing existing methodology.

2. Because of the concern that all the laboratories would be using the same procedure and, therefore, a possible bias could exist in the data base generated, some validation of analytical methods should be implemented by other laboratories and/or methods. NBS could serve this function since they are using different analytical methods for their analyses on selected specimens and on the intercalibration materials.

3. The following recommendations were made concerning future intercalibration studies:

a. Statisticians should prepare a design for future round robins ( $R$. Paule of NBS would be willing to work with NOAA on the design).

b. Appropriate existing materials for use in such round robins should be identified.

c. The appropriate round robin coordinator should be selected and the participants identified. Participants in addition to the NMFS labs and the Mussel Watch contractors should be solicited. 
d. Results should be evaluated and returned to the participants. e. Benchmark values for the intercalibration materials, derived from the round robin study, should be determined and provided to the laboratories after the study.

4. The methods for quantification of PCBs should be re-examined and improvements suggested. The criteria for the selection of representative $P C B$ congeners for quantification should be examined.

5. A mechanism should be established to identify research needs and concerns relevant to the NS\&T program.

\section{REFERENCE}

1. W. D. Macleod, Jr., D. W. Brown, A. J. Friedman, D. G. Burrows, 0. Maynes, R. W. Pearce, C. A. Wigren, and R. G. Bogar, Standard Analytical Procedures of the NOAA National Analytical Facility, 1985-86, Extractable Toxic Organic Compounds, 2nd ed., National Marine Fisheries Service, Seattle WA (1985). 


\section{INORGANIC METHODS WORKSHOP SUMRARY}

\section{T. C. Rains}

National Bureau of Standards

Dr. Shier Berman opened the discussion by reviewing the interlaboratory data presented earlier in the day. From the data presented, it was quite obvious that major problems existed in the determination of the 17 elemerts in estuanine sediments, Nio's A, B, C, and D. Some attendees expressed the opinion that different methods of sampie preparation may have contributed to the wide variation in the resilts. The preferred sample preparation would be to have just one dissolution procedure for the determination of all 17 elements. Since As, Se, Hg, Si: Al, and etc. are being requested in a wide variety of matrices and concentration, it wolid appear that no one method could be used to prepare an estuarine seciment fo: the determination of all the elements of interest. Then the question acose, if dissoiution is the major problem, why not submit a solution of an estuarine sediment together with the samples for the next evaluation? Any differences in measurements would confirm sample digestion as the source of error. The response from the attendees to this question was mixed.

The question of what range of precision and accuracy is acceptable was raised. Only NOAA can answer that question, and the NOAA representatives present were not able to give exact values, but only stated a desire to have state-of-the-art precision and accuracy.

The sample size was discussed. From the discussion, it became apparent that the contract laboratories were using 10-100 $\mathrm{mg}$ test portions in a pressure vessel. This small sample size is sure to lead to a wide variability in the results since the homogeneity of the sediments are not known at this level. Shier Berman suggested using $250 \mathrm{mg}$ as a minimum sample weight. The discussion that followed indicated that the method being used by the contract laboratories is as follows: 10-100 $\mathrm{mg}$ in Teflon pressure vessel, addition of $\mathrm{HF}$ and $\mathrm{HNO}_{3}$, heat for 2 hours, cool, add $\mathrm{H}_{3} \mathrm{BO}_{3}$ and proceed with the analysis by ICP or AAS. Any remaining solids were ignored. For the one or two laboratories using $\mathrm{HF}, \mathrm{HNO}_{3}$, and $\mathrm{HClO}_{4}$ in an open beaker, As, $\mathrm{Se}, \mathrm{Cr}$, and $\mathrm{Si}$ are sure to be low. CRC and NBS representatives suggested that at least three dissolution procedures be used. Samples for As and Se should be dissolved under reflux conditions, Si by a basic fusion and the remaining elements by $\mathrm{HF}, \mathrm{HNO}_{3}$, and $\mathrm{HClO}_{4}$ digestion. The 5-10 percent carbon should be destroyed before analysis.

The question of precision was raised again. It was generally agreed that 10 percent should be adequate for the trace elements, but $1-2$ percent was needed for the majors such as Si, Fe, and Al. This higher degree of precision for the majors is essential since the trace elements are being ratioed to the major elements.

A plea was made for four different types of sediments (high-organic with -15-208 organic material, carbonate, $\mathrm{Al} / \mathrm{Si}$ base, and $\mathrm{SiO}_{2}$ ). As an 
example, the sediments from Baltimore harbor after drying will burn. A strong recommendation was made for the preparation of the above four types of sediments to be used as controls.

Another potential problem arose during the discussion, namely that of making multiple-dilutions for the determination of the major elements by ICP. The data presented by Shier Berman showed 25-40 percent variation, yet each laboratory stated that they can do $2-3 \%$ precision for the majors. Also, a precise value doesn't always mean an accurate value.

$\mathrm{X}$-ray technique had problems in calibration. Standards for the various matrices could be of help to the technique.

While the negative aspects were discussed at length, on the positive side, $\mathrm{Zn}, \mathrm{Cu}, \mathrm{Pb}$, and $\mathrm{Cd}$ were being determined at an exceptional level.

When limits of detection (IOD) are reported, NOAA wants to know how the LODs are determined. Shier Berman will send to each laboratory a document explaining how to calculate LOD.

The subject of tissue was raised. In general, the attendees agreed to hold the tissue sample until a round-robin set has been analyzed. These samples should be available in late March or April. 


\title{
Long-Term Goals* \\ John K. Taylor \\ National Bureau of Stancards
}

\begin{abstract}
If expectations (of users) are not met = then all of the debates, the round-robin tests, the commitzee and task-group work, and lofty statements of involvement with quality and commitment to excellence have not been productive.
\end{abstract}

The user of data must have accurate results otherwise they will have limited if any value and even may be misleading and engender erroneous conclusions. The long-term (and short-term) goals of every laboratory reporting data should be to always get accurate results.

If the "same" result cannot be obtained on the same sample at various times or situations, what confidence can anyone have in any result, and what confidence can anyone have in results on different samples?

The indicators for sameness and accurate results are precision and bias which must be evaluated continually. Appropriate evaluation samples, used consistently and the results control charted are the best indicators of the stability of a measurement process. When evaluation samples are characterized accurately (reference materials) bias can be evaluated as well. Every laboratory reporting data must have its own estimation of its measurement uncertaincy and have documented evidence to support it. This is the first requirement that must be met in order to report data. This may be called INTERNAL CONFIDENCE.

After, and only after INTERNAL CONFIDENCE is established, a laboratory should seek EXTERNAL CONFIRMATION of its internal evaluation of measurement uncertainty. This may reveal unsuspected bias (which is difficult for a laboratory to evaluate in isolation) but there should be no discrepancies between internal and external estimates of precision.

EXTERNAL CONFIRMATION of measurement quality is best achiered by the use of appropriate certified reference materials. Round robins are useful, and are especially so when certified reference materials are not available. However, the samples used in round robins should simulate the normal test samples more closely than any available reference material.

*This paper was on the program but was not presented, due to time Iimitations. 
The requirements for round-robin samples are essentially the same as those for reference materials. They must have

$$
\text { -close matrix match }
$$

-sufficient homogeneity

and they should be

- accurately characterized

The first requirement is necessary if inferences are to be made on test sample performance from round-robin performance. The second is necessary to distinguish measurement variance from sample variance.

Because precision can be evaluated satisfactorily from the on-going measurements of a laboratory, the primary function of a round-robin should be to evaluate accuracy, hence the samples should be characterized accurately. Homogeneous uncharacterized materials can qualitarively identify that bias exists between laboratories but they cannot be used to quantitatively evaluate bias. Accordingly, sufficient work should be done on the samples to elevate them to reference material status, to the extent possible.

Round-robins are of limited use unless the resulting data are critically analyzed. Appropriate corrective actions should be sought for each problem discovered otherwise the exercise has been futile.

Afrer a laboratory has established INTERNAL CONFIDENCE and EXIERTAL CONFIRMATION of the quality of its data for evaluation samples, it must perform all of its measurements using appropriate quality assurance procedures so that quantitative limits of uncertainty can be reported for all of its data. This requires

-Use of appropriate methodology

- Adequate calibration

- Proper application

- Maintenance of statistical control

Quality assurance is not a one-time effort but a continuing activity. The goal must be elimination of defects. It is a never ending effort =0 improve quality and productivity. Only by continuous and diligent effort will a laboratory achieve its goal to always get accurate results.

Monitoring programs can achieve their goals only as the individual laboratories achieve their goals. Intercalibration exercises are necessary but their purpose should be EXTERNAL CONFIRMATION. More effort needs to be expended on the development of suitable certified reference materials so that laboratories can have INTERNAI CONFIDENCE for all of their data. 


\section{RECOMMENDATIONS}

- Laboratories Must Attain Statistical Control

- Laboratories Must Constantly Demonstrate Maintenance of Statistical Control

- Control Charts Can Provide Best Evidence for Both

- Use Internal Reference Materials to Determine Stability

- Use Certified Reference Materials to Demonstrate Accuracy

- Use Both in Control Chart Mode

- Use Control Charts of Duplicate Measurements of Actual Samples to Monitor On-Going Precision

- For Practical Purposes IRM'S and Duplicate Samples Must Bear the Burden of Monitoring Statistical Control

- Well Chosen Generic CRMS Should be Used to Monitor for Accuracy 


\section{Certified Reference Materials Currently Available for \\ Use in NOAA Programs*}

Willie E. May

The increasing requirements for accuracy in chemical analysis and the necessity to interrelate and combine data sets from several laboratories or from the same laboratory over time have created a need for well-characterized, stable reference materials [1]. Reference materials of various types may be utilized for calibrating and/or determining the performance of analytical instrumentation and validating analytical methods and procedures.

In 1977 the International Organization for Standardization (ISO) defined a reference material (RM) as "a material or substance one or more properties of which are sufficiently well established to be used for the calibration of an apparatus or for the modification of a measurement method". A certified reference material (CRM) was defined as " a reference material accompanied by, or traceable to, a Certificate stating the property values concerned, issued by an organization, public or private, which is generally accepted as technically competent". The National Bureau of Standards (NBS) issues Standard Reference Materials (SRMs) which are a special class of CRMs that have been carefully analyzed and certified by NBS.

SRM's that are available from NBS and appropriate for use in the analysis of marine samples are provided below along with a brief description of each. Certificates of Analysis for each are provided in Appendi: $C$. A complete compilation of CRM's available from other International standards organizations can be found in "Available Standards for Use in the Analysis of Marine Materials" by David Russell [2].

\section{NBS CALIBRATION SOLUTIONS (ORGANIC)}

Organic calibration solution SRM's are intended primarily for establishing chromatographic retention times and determining instrument response factors for the compounds included in each. They may also be used to fortify samples with known amounts of the certified compounds included (e.g. for recovery studies or quantitation based on the method of standard additions)

* 1583 ChIorinated Pesticides in Isooctane Certified concentration values for four and information value for one chlorinated pesticide.

*This paper was on the program but was not presented due to time limitations. 
* 1585 PCB Congeners in Isooctane

Certified concentration values for eight chlorinated biphenyl congeners.

* 1586 Isotopically Labeled and Unlabeled Priority Pollutants in Methanol

Separate solutions of both labeled and unlabeled compounds. Certified concentration values for the ten components in one solution are for compounds with either a deuterium or carbon-13 label. The same compounds are certified in the other solution except that they contain no isotope other than those naturally occurring.

* 1614 Dioxin (2,3,7,8-TCDD in Isooctane)

Separate solutions with certified concentration values for carbon-13 labeled and unlabeled 2,3,7,8-TCDD.

* 1647 PAH in Acetonitrile

Certified concentration values for the $16 \mathrm{PAH}$ on the EPA list of priority pollutants.

\section{NBS CALIBRATION SOLUTIONS (INORGANIC)}

These aqueous solutions are intended primarily for use in atomic absorption, optical emission spectrometry, spectrophotometry, or any other technique that requires aqueous solutions for calibration. These SRM's may also be used as primary standards for verifying the accuracy of secondary and laboratory standards.

* 1641 Mercury in Water $(\mu \mathrm{g} / \mathrm{mL})$

* 1542 Mercury in Water ( $\mathrm{ng} / \mathrm{mL}$ )

* 1643B Trace Elements in Water

Aqueous solution of 18 elements, each at $\mathrm{ng} / \mathrm{mL}$ concentrations.

* 2121-2129 Spectrophometry Standard Solutions

Each SRM in this series contains four single element solutions contained in individual bottles.

NBS NATURAL MATRIX MARINE SRM'S

* 1566 Oyster Tissue (in preparation)

This material will issued freeze-dried and will have certified values for selected trace elements. Information values (by one technique only) will be provided for selected chlorinated pesticides, PCB congeners, and PAH if present in measurable concentrations.

* 1588 Cod Liver Oil (co be available in Nov./87) This material is intended for use as a surrogate for a 


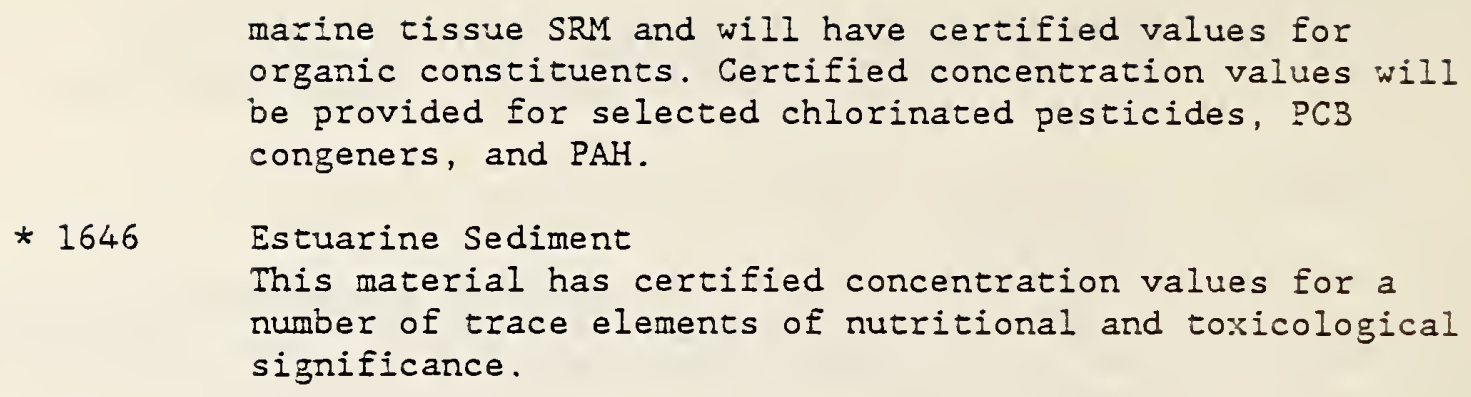

FUTURE REFERENCE MATERIALS NEEDS

It was the consensus of the attendees that the certified reference materials of most urgent need were a tissue homogenate and a natural sediment ( preferably wet/frozen) with certified concentzation values for selected chlorinated pesticides, PCB congeners, and PAH. Reference Materials currently exist that are appropriate for use in providing quality assurance for trace element analyses of similar matrices.

\section{References}

[1] Taylor, John K.," Reference Materials-What They are and How They Should be Used", Proceedings of the Symposium on Reference Materials and Their Use in the Nuclear Fuel Cycle, Aug. 8, 1982, Knoxville, TN.

[2] Russell, D. S., "Available Standards for Use in the Analysis of Marine Materials", Report No. 8, NRCC No. 23025, Marine Analytical Chemistry Standards Program, National Research Council of Canada. 


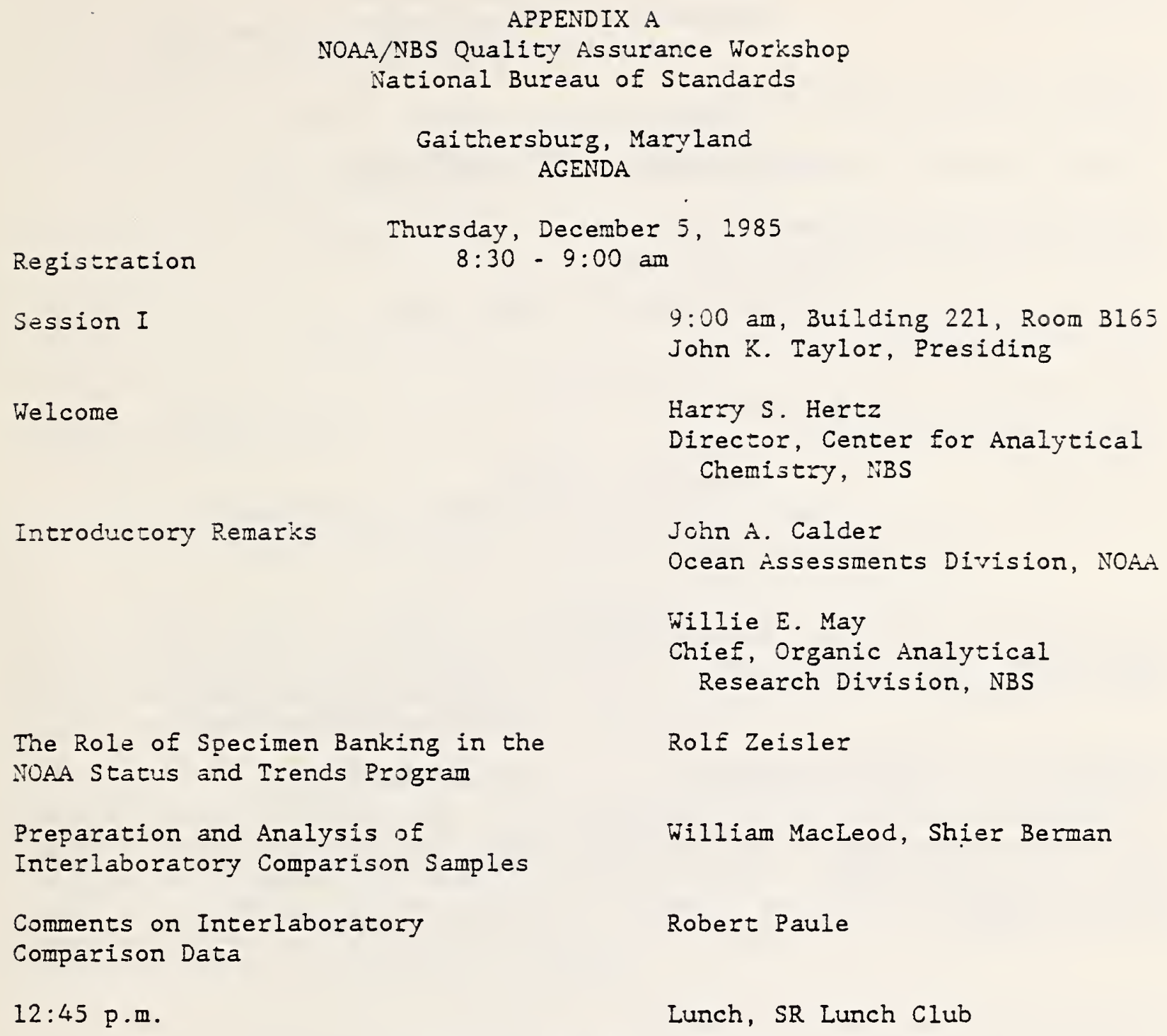

Session I

Welcome

Introductory Remarks

The Role of Specimen Banking in the

NOAA Status and Trends Program

Preparation and Analysis of

Interlaboratory Comparison Samples

Comments on Interlaboratory

Comparison Data

$12: 45$ p.m.

9:00 am, Building 221, Room B165

John K. Taylor, Presiding

Harry S. Hertz

Director, Center for Analytical

Chemistry, NBS

John A. Calder

Ocean Assessments Division, NOAA

Willie E. May

Chief, Organic Analytical

Research Division, NBS

Rolf Zeisler

William Macleod, Shier Berman

Robert Paule

Lunch, SR Lunch Club

Thursday, December 5, 1985

$$
\text { 2:00 p.m. }
$$

Session IIA. Organic Methods Workshop
a. Review of Interlaboratory Data
b. Critical Evaluation of Analytical
Methods Used in NOAA Program

Session IIB. Inorganic Methods Workshop

a. Review of Interlaboratory Data

b. Critical Evaluation of Analytical Methods Used in NOAA Program

$7: 00 \mathrm{pm}$

$7: 30 \mathrm{pm}$
Building 221, Room B165

Stephen A. Wise, Presiding

Building 220, Room A340

Theodore C. Rains, Presiding
Social Hour

Sir Walter Raleigh Inn Dinner 
Session III

Organic Methods Workshop Sumnary

Inorganic Methods Workshop Summary

Long-Term Quality Assurance Goals and

Practices Accuracy \& Precision Goals

NBS SRM's Currently Available for

Use in NOAA Program

Future Reference and Standard

Reference Material Needs

12:30 p.m.
Building 221, Room B165

Willie E. May, Presiding

Stephen A. Wise

Theodore C. Rains

John K. Taylor

Willie E. May

Willie E. May, Discussion Leader

Lunch, Dining Room C

$$
\begin{gathered}
\text { Friday, December 6, } 1985 \\
\text { 2:00 p.m. }
\end{gathered}
$$

Session IV

Protocols for Euture Round-Robin Exercises

Protocols for Sampling

Closing Remarks
Building 221, Room B165

John A. Calder, Presiding

Robert Paule

Rolf Zeisler

John A. Calder, Willie E. May 


\title{
U.S. DEPARTMENT OF COMMERCE NATIONAL BUREAU OF STANOARDE WASHIMOTON, D.C. 20234
}

\section{$552-86-009$ \\ REPORT OF ANALYSIS}

\author{
MOAA INTERCALIBRATION SEDTMENT
}

\author{
Submitted to: \\ Join A. Calder \\ Gunnar Lauenstein \\ Ocean Assessment Division \\ National Oceanic and Atmospheric Administration
}

Three samples of D-3 sediment were received October 9, 1985 from the National Marine Fisheries Service (NMFS) Laboratory, Seattle, FA. These samples had been homogenized and bottled by the MMS laboratory. The samples were kept Erozen at $-20^{\circ} \mathrm{C}$ until preparation for analysis.

For analysis, a sample of four to five grams of wet sediment was weighed to the nearest tenth of a milligram. The weighed sample was placed in a mortar containing approximately ten grams of sodium sulfate and then covered with another approximately ten grams of sodium sulfate. The sediment plus sodium sulfate was then ground to "dry" the sediment. At this point the sediment and sodiun sulfate were placed in a glass thimble and Soxhlet extracted for sixteen hours using $200 \mathrm{~mL}$ of methylene chloride.

After Soxhlet extraction, the methylene chloride extract was concentrated to approximately $500 \mu \mathrm{L}$ using nitrogen gas. The concentrate was then pipetted onto a precleaned silica Sep-Pak and eluted with $15 \mathrm{~mL}$ of 10 s methylene chloride in hexane. The eluent from the Sep-Pak was concentrated to $200 \mu \mathrm{L}$ for fractionation by normal-phase liquid chromatography on a semi-preparative aminosilane column $\left(\mathrm{LC}-\mathrm{NH}_{2}\right)$.

In the case of the polycyclic aromatic hydrocarbons (PAHs), the mobile phase used for LC- $\mathrm{NH}_{2}$ Eractionation was $2 \%$ methylene chloride in hexane. The alkane fraction was eluted first and discarded. The aromatic fraction was collected

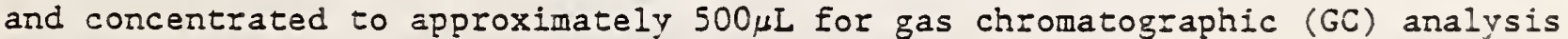
using a flame ionization detector (FID) or liquid chromatographic (IC) analysis with wavelength programmed spectroftuorometric detection. This approach has been utilized for the analysis of PAH in several other matrices (1-6).

In the case of the polychlorinated biphenyls (PCBs) and pesticides, the mobile phase used for LC- $\mathrm{NH}_{2}$ fractionation was hexane for the PCBs and relatively nonpolar pesticides and 5 methylene chloride in hexane for the more polar pesticides. These separate fractions were concentrated to approximateiy $500 \mu$ for GC analysis using an electron capture detector (ECD). A publication describing this fractionation procedure is in preparation ( 7 ). 
Four samples were analyzed by GC-FID and three samples by LC-fluorescence for PAHs. Three samples were analyzed by GC-ECD for the PCBs and pesticides. In the case of the GC-FID analysis, 1 -methylpyrene was added as an incernal standard before Soxhlet extraction. For LC-fluorescence analys is, phenanthrene-d $d_{10}$. Fluoranthene-d $d_{10}$, and perylene-d $d_{12}$ were added as internaI standards, again before Soxhlet extraction. Finally, for the GC-ECD analysis, $\mathrm{PCB} \# 10$ and $\# 198$ (2,6-dichlorobiphenyl and

$2,2^{\prime}, 3,3^{\prime}, 4,5,5^{\prime}, 6$-octachlorobiphenyl, respectively) for the PCB fraction and perdeuterated DDT for the pesticide fraction were added as internal standards before Soxhlet extraction. Calibration solutions were also Soxhlet extracted, concentrated, and fractionated in a manner similar to that for the sediment samples.

The GC conditions used for the PAH analysis were:

Column:

Immobilized nonpolar (DB-5 j\&ii) fused silica capillary $30 \mathrm{~m} \mathrm{X} 0.25 \mathrm{~mm}$ id X 0.25 um coating thickness

Injector:

Sample size:

Injector temperature:

Manual, all glass-splitting

FID temperature:

$2 \mu \mathrm{L}$

$300^{\circ} \mathrm{C}$

$300^{\circ} \mathrm{C}$

Initial column temperature:

$150^{\circ} \mathrm{C}$ for $2 \mathrm{~min}$

Rate:

Final temperature:

$4^{\circ} / \min$

$280^{\circ} \mathrm{C}$ for $15 \mathrm{~min}$

Cartier gas:

Splic flow:

Hydrogen at 18 psi

Helium make-up gas:

$25 \mathrm{~mL} / \mathrm{min}$

$30 \mathrm{~mL} / \mathrm{min}$

For PCB and pesticide analysis, the same column, injector, and sample size, and injector temperature were used. The remaining conditions were as follows:

ECD temperature:

Initial column temperature:

Rate:

Final temperature:

Carrier gas:

Split Flow:

Nitrogen make-up: $320^{\circ} \mathrm{C}$

$180^{\circ} \mathrm{C}$ with no initial hold

$3^{\circ} / \mathrm{min}$

$270^{\circ} \mathrm{C}$ for $10 \mathrm{~min}$

Helium at 18 psi

$25 \mathrm{~mL} / \mathrm{min}$

$30 \mathrm{~mL} / \mathrm{min}$

The conditions used for LC-fluorescence analysis were as follows:

Column:

Reversed-phase octadecylsilane column, $5 \mu \mathrm{m}$ particle size, $4.6 \mathrm{~mm}$ i.d. $\times 25 \mathrm{~cm}$

(Vydac 201TP; Lot 540056, No. 20).

Chromatographic Conditions: Linear gradient from 40 acetonitrile in water to 1008 acetonitrile in $50 \mathrm{~min}$ at $1.5 \mathrm{~mL} / \mathrm{min}$; then return to 40 s acetonitrile in water in 5 min; remain at these conditions for 2 min; then stop flow until next injection. 
Fluorescence Detection:

Detector excitation and emission wavelengths were programmed as follows:

\begin{tabular}{|c|c|c|c|}
\hline $\begin{array}{l}\text { Time } \\
\text { (min) }\end{array}$ & $\begin{array}{l}\text { Excitation } \\
\text { (nm) }\end{array}$ & $\begin{array}{c}\text { Emission } \\
(\mathrm{nm})\end{array}$ & $\begin{array}{c}\text { PAH } \\
\text { Detemined }\end{array}$ \\
\hline 0 & 250 & 360 & $\begin{array}{l}\text { Phenanthrene- } d_{10} \\
\text { Pherantirene }\end{array}$ \\
\hline 19.5 & 250 & 400 & Anthracene \\
\hline 21.5 & 285 & 450 & $\begin{array}{l}\text { Fluoranthene }-d_{10} \\
\text { Fluoranthene }\end{array}$ \\
\hline 24.3 & 330 & 385 & Pyrene \\
\hline 27.0 & 285 & 385 & $\begin{array}{l}\text { Benz [a] anthracene } \\
\text { Chrysene }\end{array}$ \\
\hline 33.8 & 400 & 440 & $\begin{array}{l}\text { Perylene }-d_{12} \\
\text { Perylene }\end{array}$ \\
\hline 37.0 & 295 & 405 & $\begin{array}{l}\text { Benzo[a]pyrene } \\
\text { Benzo[k] fluoranthene }\end{array}$ \\
\hline 43.5 & 380 & 405 & Benzo[ghi]perylene \\
\hline 46.5 & 300 & 500 & $\begin{array}{l}\text { Indeno }[1,2,3 \text {-cd }]- \\
\text { pyrene }\end{array}$ \\
\hline
\end{tabular}

Three internal standards were used for the quantification of the PAH as follows: phenanthrene-d 10 was used to quantity phenanthrene and anthracene; fluoranthene-d 10 was used to quantify fluoranthene, pyrene, benz[a] anthracene, and chrysene; and perylene-d 10 was used to quantify perylene, benzo[a]pyrene, benzo[k] fluoranthene, benzo [ghi]perylene, and indeno[1,2,3-cd]pyrene. Detector response factors were determined using SRM 1647 with perylene and the internal standards added. Three samples were analyzed with triplicate analyses of each sample.

The results of the PAH determinations are summarized in Table 1 , and the PCB and pesticide determininations are summarized in Table 2. Note that the concentrations are given in terms of dry weight of the sediment. For the dry weight determination, three samples of approximately 4 grams (each weighed to the nearest tenth of a milligram) were placed in an oven set at $110^{\circ} \mathrm{C}$ overnight. The following morning the samples were reweighed to determine the weight lost during the drying. The wet sediment was found to contain 45.847 water.

As shown in Table 1, the agreement between the GC-FID and the IC-fluorescence results is good. The anthracene and perylene values are both higher for the GC analysis which has also been found for the determination of these tro compounds in other types of samples (3-6). The LC values are probably more accurate for these two compounds since the fluorescence conditions used were ooth more sensitive and selective for these compounds. In the case of chrysene, the GC value includes triphenylene since these compounds are not separable on the column used. 
The concentration of the pesticides in this sediment are low as can be seen in Table 2; whereas, the PCBs are at a higher level. This method of fractionation is convenient for reducing the interferences between the PCB and pesticide peaks during GC analysis.

Further details and data from these analyses can be found in the notebooks of M. Schantz $\neq 10$, pages $1-50$ and in S. Wise Notebook--PAH Measurements, 1986.

intehele Michants

Michele M. Schantz $\theta$

Research Chemist

Organic Analytical Research Div.

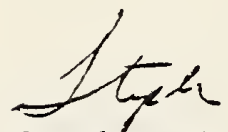

Stephen $\mathrm{N}$. Chesler

Supervisory Research Chemist

Organic Aralytical Research Div.

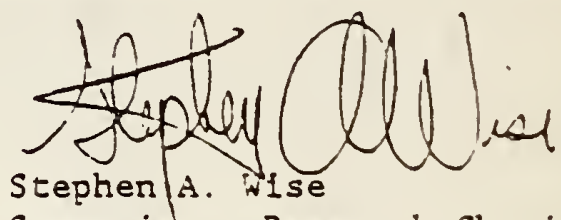

Superrisory Research Chemise Organic Analytical Researci Div.

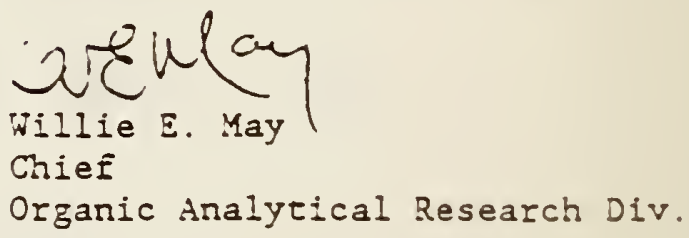

March 3, 1986 
Table 1

Concentrations of the PAH in the D-3 Sediment

Compound

$$
\begin{aligned}
& \text { Concentration }(\mu g / g \text { dry reight) } \\
& \text { GC }^{a, C}
\end{aligned}
$$

\begin{tabular}{lll}
\hline Phenanthrene & $2.42 \pm 0.22$ & $2.28 \pm 0.17$ \\
Anthracene & $0.71 \pm 0.06$ & $0.49 \pm 0.04$ \\
Fluoranthene & $3.66 \pm 0.43$ & $3.42 \pm 0.19$ \\
Pyrene & $3.93 \pm 0.36$ & $3.64 \pm 0.26$ \\
Benz[a]Anthracene & $1.84 \pm 0.20$ & $1.39 \pm 0.11$ \\
Chrysene & & $1.87 \pm 0.12$ \\
$\quad$ +Triphenylene & $2.70 \pm 0.19$ & \\
Benzo[e] Pyrene & $1.86 \pm 0.10$ & \\
Benzo[a]Pyrene & $2.54 \pm 0.17$ & $2.14 \pm 0.14$ \\
Perylene & $0.77 \pm 0.04$ & $0.57 \pm 0.03$ \\
Benzo[k]Fluoranthene & & $2.14 \pm 0.12$ \\
Indeno[1,2,3-cd]pyrene & & $1.43 \pm 0.08$
\end{tabular}

average of 4 extracts each analyzed 3 times.

bAverage of 3 extracts each analyzed 3 times.

Uncertainty is \pm 1 standard deviation of the mean. 
Table 2

Concentrations of the PCBs and Pesticides in the D-3 Sediment

Compound

IC Fraction ${ }^{a}$

Concentration $b, c$

(ng/g dry weight)

2,4'-Dichlorobiphenyl

$2,4^{\prime}, 5$-Trichlorobiphenyl

2. 2', 4, 4'-Tetrachlorobiphenyl

$2,2^{\prime}, 4,4^{\prime}, 5$-Pentachlorobiphenyl

$2,2^{\prime}, 4,4^{\prime} 5,5^{\prime}$-Hexachlorobiphenyl

$2,2{ }^{\prime} 3,4,5,5^{\prime}, 6$-Heptachlorobiphenyl

$2,2^{\prime}, 3,3^{\prime}, 4,4^{\prime}, 5,5^{\prime}$-Octachlorobiphenyl 1

$2,2^{\prime}, 3,3^{\prime}, 4,4^{\prime}, 5,5^{\prime}, 5$-Nonachlorobiphenyl 1

Hexachlorobenzene

Heptachlor

Aldrin

$0, P^{\prime} D D E$

$p, p^{\prime}$ DDE

Mirex

Lindane

Heptachlor epoxide

alpia-Chlordane

Transnonachlor

Dieldrin

$\circ, \mathrm{P}^{\prime} \mathrm{DDT}$

$\mathrm{p}, \mathrm{p}^{\prime} \mathrm{DDT}$

1

1

1

1

1

1

2

2

2

2

2

2

2
$<0.5$

$<0.5$

$9.5 \pm 0.4$

$117 \pm 5$

$127 \pm 8$

$22.2 \pm 1.0$

$10.0 \pm 0.4$

$18.2 \pm 1.5$

$<0.5$

$<0.3$

$<0.5$

$<0.5$

$1.9 \pm 0.1$

$<0.3$

$<0.5$

$0.6 \pm 0.1$

$<0.2$

$0.9=0.1$

$<0.3$

$1.4 \pm 0.1$

$2.4=0.1$

alC fraction I (PCB) is composed of the more nonpolar compounds compared to fraction 2 (pesticide).

${ }^{b}$ Average of three extracts each analyzed 3 times.

Uncertainty is \pm 1 standard deviation of the mean. 
1. Wise, S. A., Chesler, S. N., Hertz, H. S., Hilpert, L. R., and May, W. E., A Chemically Bonded Aminosilane Stationary Phase for the High-Perfornance Liquid Chromatographic Separation of Polynuclear Aromatic Compounds, Anal. Chem. 49 (14), 2306-2310 (1977).

2. Hertz, H. S., Brown, J. M., Chesler, S. N., Guenther, F. R., Hilpert, I. R., May, W. E., Parris, R. M., and Wise, S. A., Determination of Individual Organic Compounds in Shale Oil, Anal. Chem. 52 (11), 1650-1657 (1980).

3. May, W. E., Chesler, S. N., Hilpert, I. R., Hertz, H. S., Rebbert, R. E., Vogt, C. R., and Wise, S. A., Characterization of Polycyclic Aromatic Hydrocarbons in Air Particulate Extracts by Liquid and Gas Chromatographic Methods: Identification and Analysis of Organic Pollutants in $A i z, I$. $\vec{R}$. Keith, ed., Butterworth Publications, Noburn, MA, 197-229 (1984).

4. May, W. E. and Nise, S. A., Liquid Chromatographic Determination of Polycyclic Aromatic Hydrocarbons in Air Particulate Extracts, Anal. Chem. $56,225-232(1984)$.

5. Wise, S. A., Chesler, S. N., Hilpert, L. R., May, W. E., Rebbert, R. E., and Vogt, C. R., Characterization of Polycyclic Arcmatic Hydrocarbon Mixtures from Air Particulate Samples Using Liquid Chromatography, Gas Chromatography, and Mass Spectrometry, Polgnuclear Aromatic Hydrocarbons: Mechanisms, Methods, and Metabolism, M. Wooke and A. J. Dennis, eds., Battelle Press, Columbus, $\mathrm{CH}, 1413-1427$ (1983).

6. Kline, W. F., Wise, S. A., and May, W. E., The Application of Perdeuterated Polycyclic Aromatic Hydrocarbons (PAH) as Internal Standards for the Liquid Chromatographic Determination of PAH in a Petroleum Crude Oil and Other Complex Mixtures, J. Liquid Chromatogr. $\underline{8}$ (2), 223-237 (1985).

7. Parris, R. M., Wise, S. A., and Chesler, S. N., in preparation. 



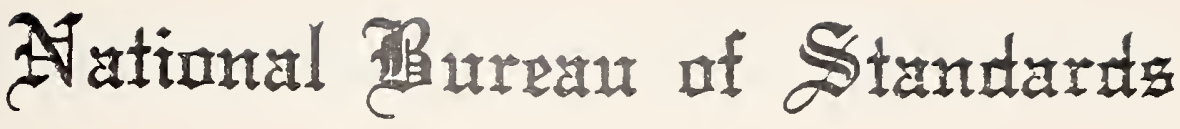

\section{UTertifitate af Antralugim}

\section{Standard Reference Material 1583}

\section{Chlorinated Pesticides in 2, 2, 4-Trimethylpentane}

This Standard Reference Material (SRM) is intended primarily for calibrating methods used in the determination of the chlorinated pesticides certified in this SRM. It can also be used for the purpose of adding known amounts of these pesticides to a sample in recovery studies or to fortify samples with known concentrations of these pesticides. The Chemical Abstracts Service (CAS) Nomenclature, common names, and CAS Registry Number of the six pesticide components are listed in Table 1.

Certified Concentrations of the Pesticides: The certified concentrations and estimated uncertainties of the pesticides are shown in Table 2.

Each value is based on the concentration calculated from the mass of the pesticide added to a known mass of 2,2,4trimethylpentane (isooctane) and on the analytical results obtained by using capillary gas chromatography with electron capture detection (GC/ECD). The pesticices used were procured as being $99+$ percent pure and $G C$ and $G C / M S$ analyses supported these claims. Table 3 shows the calculated concentrations and the concentrations obtained by the analytical methods used in the certification. A noncertified concentration of heptachlor epoxide, which is given for information only, is also listed in Table 3.

\section{NOTICE AND WARNING TO USERS}

Handling: Pesticide-containing materials are reported to be toxic and should be handled with care. Proper disposal methods should be used.

Expiration of Certification: This certification is valid within the specified uncertainty limits for one year from the date of purchase. In the event that the certification should become invalid before then, purchasers will be notified by NBS.

Storage: Sealed ampoules, as received, should be stored in the dark at temperatures between 10 to $30^{\circ} \mathrm{C}$.

Use: Samples of the SRM for analysis should be withdrawn from ampoules (at $23 \pm 5^{\circ} \mathrm{C}$ ) immediately after opening and used without delay for the certified values listed in Table 2 to be valid within the stated uncertainty. Certified values are not applicable to material in ampoules stored after opening, even if they are resealed.

Preparation and analytical determinations were performed at the Center for Analytical Chemistry, Organic Analytical Research Division, by S.N. Chesler, D.P. Enagonio, L.R. Hilpert, R.M. Parris, and C.R. Vogt.

Consultation on the statistical design of the experimental work and evaluation of the data was provided by K.R. Eberhardt of the Statistical Engineering Division.

The coordination of the technical measurements leading to the certification was under the direction of S.N. Chesler. W.E. May, and R.M. Parris.

The technical and support aspects involved in the preparation, certification, and issuance of this Standard Reference Material were coordinated through the Office of Standard Reference Materials by R. Alvarez. 


\section{PREPARATION AND ANALYSIS}

Pesticides and 2.2,4-trimethylpentane were obtained from commercial sources. The pesticide solution was prepared at NBS by weighing and mixing the individual pesticides and 2,2,4-trimethylpentane. This solution was dispensed into $2-\mathrm{mL}$ a mber ampoules which were then flame sealed. Aliquots from randomly selected ampoules were analyzed with a gas chromatograph equipped with an injector splitter and a $30 \mathrm{~m} \times 0.25 \mathrm{~mm}$ nonpolar, immobilized phase wall-coated open-tubular column. A constant current $\mathrm{Ni}^{63}$ electron capture detector was used for these analyses. Quantitative results were obtained by using 2,4',5-trichlorobiphenyl and 2,2',4,5,5'-pentachlorobiphenyl as internal standards (IS). Calibration solutions consisting of weighted amounts of the pesticides and IS compounds in $2,2,4$ trimethylpentane were chromatographed to determined analyte response factors.

Table 1

Chemical Abstracts Service (CAS) Nomenclature and Registry Number ${ }^{2}$

Pesticide

$\gamma-\mathrm{BHC}$

Lindane

$\delta-B H C$

Aldrin

Heptachlor Epoxide

4,4'-DDE

p, p'-DDE

4,4'-DDT

p,p'-DDT

\section{CAS Nomenclature}

(1 $\alpha, 2 \alpha, 3 \beta, 4 \alpha, 5 \alpha, 6 \beta)-1,2,3,4,5,6$-hexachlorocyclohexane

(1 $\alpha, 2 \alpha, 3 \alpha, 4 \beta, 5 \alpha, 6 \beta)-1,2,3,4,5,6$-hexachlorocyclohexane

$(1 \alpha, 4 \alpha, 4 \mathrm{a} \beta, 5 \alpha, 8 \alpha, 8 \mathrm{a} \beta)-1,2,3,4,10,10$-hexachloro- $1,4,4 \mathrm{a}, 5,8,8 \mathrm{a}$ hexahydro-1,4:5,8-dimethanonaphthalene

2,3,4,5,6,7,7-heptachlor-la, lb,5,5a,6,6a-hexahydro-2,5-methano$2 H$-indeno[ $[1,2$-b]oxirene

$1,1^{\prime}$-(dichloroethenylidine) bis[4-chlorobenzene]

1, 1'-(2,2,2-trichloroethylidene)bis[4-chlorobenzene]
CAS Registry Number

58-89-9

$319-86-8$

309-00-2

$1024-57-3$

$72-55-9$

$50-29-3$

'Chemical Abstracts. Tenth Collective Index, Index Guide, American Chemical Society, Columbus, Ohio, 1982 
Table 2

\section{Certified Concentrations of Pesticides in SRM 1583}

...... Concentration ${ }^{b} \ldots . .$.

\section{Compound ${ }^{2}$}

$\gamma-\mathrm{BHC}$

$\delta-B H C$

Aldrin

$p, p^{\prime}-D D E$

p,p'-DDT $\mu \mathrm{g} / \mathrm{g}$

$1.11 \pm 0.01$

$0.76 \pm 0.01$

$0.86 \pm 0.01$

$1.23 \pm 0.03$

$1.90 \pm 0.10$

\begin{tabular}{c}
$\mu \mathrm{g} / \mathrm{mL}^{\mathrm{c}}, 23^{\circ} \mathrm{C}$ \\
\hline $0.77 \pm 0.01$ \\
$0.53 \pm 0.01$ \\
$0.59 \pm 0.01$ \\
$0.85 \pm 0.02$ \\
$1.31 \pm 0.07$
\end{tabular}

See Table 1 for CAS Nomenclature.

${ }^{b}$ For each compound, the certified value is the mean of the calculated and GC/ECD determinations. The corresponding uncertainty represents the symmetrical interval about the certified yalue which encompasses the 95 percent confidence interval from the analyses that utilized gas chromatography with electron capture detection.

'The concentration and uncertainty expressed in mass/volume units are applicable for use of this material at $23^{\circ} \mathrm{C}$. Since the density of 2,24-trimethylpentane changes with temperature, the listed concentration will change by up to 1 percent of the value listed if the SRM is used at other temperatures in the $14.6^{\circ} \mathrm{C}$ to $31.4^{\circ} \mathrm{C}$ range. See "Selected Values of Properties of Hydrocarbons and Reiated Compounds," American Petroleum Institute Researci Project 44, Thermodynamic Research Center, Texas A\&M University, Table 3d, page 1, October 1952.

Table 3

Summary of Results

\begin{tabular}{lcr} 
Compound & Calculated & GC/ECD \\
\hline$y-B H C$ & $1.112 \pm 0.001$ & $1.109 \pm 0.010$ \\
$\delta-B H C$ & $0.768 \pm 0.001$ & $0.761 \pm 0.007$ \\
Aldrin & $0.861 \pm 0.001$ & $0.861 \pm 0.010$ \\
p,p'-DDE & $1.231 \pm 0.001$ & $1.232 \pm 0.025$ \\
P, $p^{\prime}-D D T$ & $1.900 \pm 0.002$ & $1.899 \pm 0.100$ \\
Heptachlor Epoxide & $\cdots$ & $0.997 \pm 0.016$ \\
"Uncertainty expressed as \pm 20 based on estimates of the precision of the weighings for the two balances used. \\
'Uncertainty expressed as 95 percent confidence interval.
\end{tabular}




\section{Uertificate of Analogis}

\section{Standard Reference Material 1585}

\section{Chlorinated Biphenyls in 2,2,4-Trimethylpentane (Isooctane)}

This Standard Reference Material (SRM) is intended primarily for use in the calibration of chromatographic instrumentation used for the determination of polychlorinated biphenyls. SR.M 1585 consists of a set of five sealed ampoules containing a solution of eight chlorinated biphenyl congeners in 2,24trimethylpentane (isooctane).

\section{CERTIFIED CONCENTRATIONS OF THE CHLORINATED BIPHEVYL CONGE.VERS}

The certified concentrations and estimated uncertainties of eight chlorinated biphenyl congeners are shown in Table 1. Each value is based on the concentration calculated from the mass of the congener added to a known mass of 2.2. terimethyipentane and on the analytical results obtained by using capillary gas chromatography with electron capture detection (GC-ECD). Calculations of the values included correction of the measured mass of each congener by its measured purity. The uncertainties listed in Table 1 include estimates of both purity and chromatographic uncertainty components.

The calculated concentrations, the concentrations determined by the GC-ECD method, and the measured purities of the compounds are given in Table 2 . The certified concentrations in Table 1 were derived from these data. The concentrations given in Table 2 have beea corrected for the purity of the congeners determined by capillary GC equipped with flame ionization detection (GC-FID).

The significance of each of the chlorinated biphenyl compounds present in SR.M 1585 is indicated in Table 3.

Expiration of Certification: This certification is valid within the specified limit of uncerainty for one year from the date of purchase. In the event that the certification should become invalid before then, purchasers will be notified by .VBS.

Storage: The sealed ampoules should be stored as received, in the dark, at temperatures between 10 to $30^{\circ} \mathrm{C}$.

Use: Samples of the SRM for analysis should be withdrawn from ampoules immediately after opeaing and used without delay for the certified values listed in Table 1 to be valid within the stated uncertainties. Certiried values are not applicable to material stored in ampoules after opening, even if the ampoules are resealed.

Preparation and analytical determinations were performed by S.N. Chesler. D.P. Enagonio, and R..M. Parris of the Organic Analytical Research Division, NBS Center for Analytical Chemistry.

Consultation on the statistical design of the experimental work and evaluation of data was provided by K. R. Eberhardt of the NBS Statistical Engineering Division.

The coordination of the technical measurements leading to the certification was under the direction of S.N. Chesler and R.M. Parris.

The technical and support aspects involved in the preparation, cerification, and issuance of this Standard Reference Material were coordinated through the Office of Standard Reference Materials by $R$. Alvarez.

January 30, 1986

Gaithersburg, MD 20899
Stanley D. Rasberry. Chisef

Office of Standard Reference Materials

(over) 


\section{PREPARATION AND ANALYSIS}

The chlorinated biphenyl compounds and 2,24trimethylpentane were obtained from commercial sources. A solution was prepared at NBS by weighing and mixing the individual compounds and $2,2,4$ trimethylpentane. This solution was dispensed into 2-mL amber ampoules which were then flame sealed. Aliquots from randomly selected ampoules were analyzed using a gas chromatograph equipped with an injector splitter and a $30 \mathrm{~m} \times 0.25 \mathrm{~mm}$ nonpolar, immobilized phase, wall-coated, open-tubular column. A constant current ${ }^{53}$. Vi electron capture detector was used for these analyses. Quantitative results were obtained by using 2,2,3,3'-tetractlorobiphenyl (CB $; 40$ ) and $2,2^{\prime}, 3,4,5,5^{\prime}$-hexachlorobiphenyl (CB \# 141) as internal standards (IS). Cailbration solutions consisting of weighted amounts of the compounds and IS compounds in 22,4trimethylpentane were analyzed chromatographically to determine analyre response factors.

The estimated purity of each chlorinated biphenyl component was determined using a gas chromatograph equipped with a $30 \mathrm{~m} \times 0.25 \mathrm{~mm}$ non-polar, immobilized phase, wall-coated, open-tubular column and a flame ionization detector. Hexane solutions of each compound were analyzed and the relative response factors of the impurities were determined using the mathod of Zoller et al.

\section{Reference}

Zoller, W., Schafer, W., Class, T., and Ballschmiter, K., Fresenius Z. Anal. Chem. 321. 247-251 (1985).

\section{Table 1}

\section{Certified Concentrations of Chlorinated Biphenyls in SR.M 1585}

No.

3

15

28

52

77

101

138

153

\section{Compound}

4chiorobiphenyl

4,4'-dichiorobiphenyl

2,4,4-trichlorobip henyl

2,27,5,5-tetrachlorobiphenyl

$3,3^{3}, 4,4^{\prime}$-tetrachlorobip henyl

2.2\%,4,5,5-pentachlorobiphenyl

$2,2^{2}, 3,4,4^{\prime}, 5$-hexachlorobip henyl

$2,2,4,4^{\prime}, 5,5$-hexachlorobiphenyl

\begin{tabular}{|c|c|}
\hline \multicolumn{2}{|c|}{ Concentration $^{2}$} \\
\hline$\mu g / g$ & $\mu \mathrm{g} / \mathrm{mL}{ }^{c}$ at $23.0^{\circ} \mathrm{C}$ \\
\hline $43.3 \pm 1.0$ & $29.9 \pm 0.7$ \\
\hline $9.53 \pm 0.08$ & $6.57 \pm 0.06$ \\
\hline $3.70 \div 0.02$ & $2.55 \pm 0.01$ \\
\hline $7.72 \pm 0.06$ & $5.32 \pm 0.04$ \\
\hline $6.62 \pm 0.05$ & $4.56 \pm 0.03$ \\
\hline $5.24 \pm 0.02$ & $3.61 \pm 0.01$ \\
\hline $2.37 \pm 0.02$ & $1.63 \pm 0.01$ \\
\hline $3.06 \pm 0.02$ & $2.11=0.01$ \\
\hline
\end{tabular}

"For each compound. the certified concentration is the mean of the calculated concentration and chromatographic dezermination. Both calculated and experimental concentrations were correced for the perceat purity of the chlorinated biphenyl componeats.

The stated uncertainty was computed as a 95\% confideace interval for the chromatographic measured value plus an allowance for systematic stror. The confidence interval reflects measuremeat ertor for both the purity of the CB congerer components as well as the concentration measuremeats ior the SRM itself. The allowance for systematic error is the magnitude of the difference between the certified value and the chromasographic determination. Ballsebmiter, K. and Zell, M., Fresenius Z. Anal. Chem. 302. 22-31 (1980).

The conceatration and uncerainty expresed in mass/volume units are applicable for use of this material at $23.0^{\circ} \mathrm{C}$. Because the density of 22 thrimethylpeatane changes with temperature, the concentration will also change as temperature changes and will be different than the value at $23.0^{\circ} \mathrm{C}$ However, the concentrations will change by las than one percent of the value listed if the SR.M is used as temperatures in the 15 to $31^{\circ} \mathrm{C}$ range. See uselected Value of Properties of Hydrocarbons and Related Compounds, American Petroleum Institute Research Project 4 , Thermodynamic Researeh Center, Texas AdM University. Table 3d, page 1, October 1952

SRM 1585

Page 2 


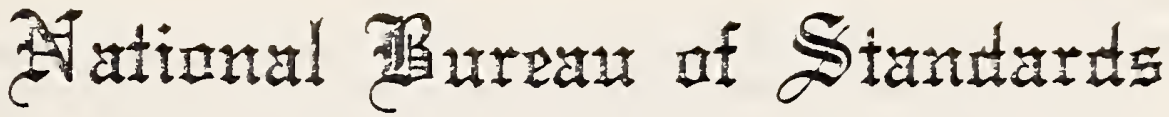

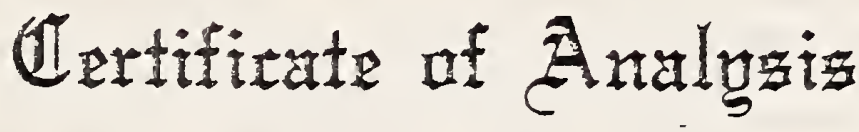

\section{Standard Reference Material 1586}

\author{
Isotopically Labeled and Unlabeled \\ Priority Pollutants in Methanol
}

This Standard Reference Material (SRM) is intended primarily for use in the evaluation and calibration of analytical instrumentation used for the determination of priority pollutants as classified by the U.S. Environmental Protection Agency (EPA). In particular this SRM may be used to calibrate and/or test a laboratory's use of EPA Analytical Methods 1624 and 1625 (as well as 624-625 and 524-525). These methods specifically require the use of combined gas chromatography/mass spectrometry (GC/MS) and the use of isotopically labeled internal standards. SRM 1586 is composed of two separate solutions. The ten Priority Pollutants in one solution (SRM 1586-2) contain either deuterium or carbon-13 while the other solution (SR:M 1586-1) contains the same compounds with no isotopes except those naturally occurring.

Certified Values of Constituent Organic Compounds: The certified values for the selected organic constituents are shown in Table 1. These certified values are based on results obtained from the gravimetric preparation of these solutions and from the analytical values determined by gas chromatography. Table 2 summarizes the calculated and analytically determined concentrations.

Notice and Warnings to User

Handling: Priority Pollutants are reported to be toxic and should be handled with care. Use proper disposal methods.

Expiration of Certification: This certification is valid, within the limits certified, for one year from the date of purchase. In the event that the certification should become invalid before then, purchasers will be notified by NBS.

Storage: Sealed ampoules, as received, should be stored in the dark at temperatures between $10-30^{\circ} \mathrm{C}$.

Use: Samples for analysis should be withdrawn immediately after opening ampoules and should be processed without delay for the certified values in Table 1 to be valid within the stated uncertainty. Certified values are not applicable to material stored in ampoules that have been opened, even if they are resealed.

Preparation and analytical determinations were performed at the Center for Analytical Chemistry. Organic Analytical Research Division, by F.R. Guenther, D.J. Pereles, R.E. Rebbert, M.J. Welch and E. White. V.

Consultation on the statistical design of the experimental work was provided by K.R. Eberhardt of the Statistical Engineering Division.

The coordination of the technical measurements leading to certification was under the direction of S.N. Chesler and W.E.. May.

The technical and support aspects involved in the preparation, certification, and issuance of this Standard Reference Material were coordinated through the Office of Standard Reference Materials by R. Alvarez.

October 16, 1984

Gaithersburg, MD 20899
Stanley D. Rasberry, Chief Office of Standard Reference Materials 
All chemicals used in the preparation of SRM 1586-1 and 1586-2 were obtained from commercial sources and were deemed the best available at the time. The chemical purities, as determined by gas chromatography, are listed in Table 3 and were used in the determination of the certified values. The isotopic purities of the compounds in SRM $1586-2$ as determined by mass spectrometry at NBS are shown in Table 4. Both solutions were prepared at NBS by weighing and mixing the ten individual compounds and the methanol solvent. Each solution was chilled and ampouled into $2 \mathrm{~mL}$-amber glass ampoules. Each ampoule was purged with nitrogen immediately before adding the solution and sealing. Aliquots from randomly selected ampoules were analyzed by gas chromatography with flame ionization detection. A glass column ( $2 \mathrm{~m} \times 2 \mathrm{~mm}$ I.D.), packed with $60 / 80$ Carbopack B and coated with $1 \%$ SP-1000 was used for determination of carbon tetrachloride and benzene. The internal standard (IS) for this anaiysis was 1,2-dichloropropane. A fused silica column ( $30 \mathrm{~m} \times 0.25 \mathrm{~mm}$ I.D. $\times 0.25 \mu \mathrm{m}$ film of bonded dimethyl polysiloxane) was used with splitless injection for the determination of the other eight components. For SRM 1586-1 (unlabeled), 0-xylene was the IS for chlorobenzene while 6-chloro-m-cresol was the IS for phenol, nitrobenzene, 2-nitrophenol, 2,4-dichlorophenol and naphthalene, and benzo(k)fluoranthene was the IS for bis(2-ethylhexyl) phthalate and benzo(a)pyrene. For SR:M 1586-2 (labeled) the same three internai standards were used but in addition bis(2-ethylhexyl) adipate was used as the IS for the bis(2-ethylhexyl) phthalate.

\section{TABLE I}

\section{Certified Concentrations of Priority Pollutants in SRM 1586}

\begin{tabular}{lc} 
Compounds & Concentration $(\mu \mathrm{g} / \mathrm{g})^{2}$ \\
\hline SRM $1586-1$ & $128.5 \pm 0.5$ \\
\hline Carbon tetrachloride & $101.1 \pm 0.8$ \\
Benzene & $133.0 \pm 0.6$ \\
Chlorobenzene & $117.0 \pm 1.3$ \\
Phenol & $126.0 \pm 1.1$ \\
Nitrobenzene & $103.6 \pm 3.2$ \\
2-nitrophenol & $102.5 \pm 0.6$ \\
2,4-dichlorophenol & $126.5 \pm 1.2$ \\
Naphthalene & $63.9 \pm 1.7$ \\
Bis(2-ethylhexyl)phthalate & $49.2 \pm 0.2$ \\
Benzo(a)pyrene &
\end{tabular}

SRM 1586-2 (See Table 3 for isotopic purity of these compounds)

\begin{tabular}{|c|c|}
\hline Carbon tetrachloride- ${ }^{13} \mathrm{C}$ & $124.4 \pm 2.1$ \\
\hline Benzene- $d_{6}$ & $99.0=0.5$ \\
\hline Chlorobenzene-ds & $144.0=1.3$ \\
\hline - Phenol-ds & $116.0=$ \\
\hline Nitrobenzene- $d_{5}$ & 134.5 \\
\hline 2-nitrophenol-d 4 & 101.9 \\
\hline 2,4-dichlorophenol-d ${ }_{3}$ & 82.2 \\
\hline Naphthalene-d8 & $126.6=1$ \\
\hline Bis[2-ethylhexyl]phthalate-d 4 & 60.4 \\
\hline Benzo(a)pyrene-d $d_{12}$ & $44.1=$ \\
\hline
\end{tabular}

"For each compound, the certified value is the mean of the calculated and chromatographic determinations. The corresponding unceraainty represents the symmetric interval about the cerufied value which covers the $95 \%$ confidence interval from the chromatographic analyses. Thus, the uncerainty reflects both random error of measurement and the systematic bias between the calculated and chromatographic values.

- Weighed as phenol-d6, but in methanol solution it converts quancitatively to phenol-ds. 


\section{TABLE 2}

Summary of Results

Compound

Priority Pollutants SRM 1586-1

Carbon tetrachloride

Benzene

Chlorobenzene

Phenol

Nitrobenzene

2-nitrophenol

2,4-dichlorophenol

Naphthalene

Bis[2-ethylhexyl]phthalate

Benzo(a)pyrene
Calculated Values,

$\mathrm{ig} / \mathrm{g}$

128.60

100.82

132.63

117.30

126.01

104.39

102.42

126.74

64.16

49.15
Analytical Values,

43,3

$128.4 \pm 0.4$

$101.3 \pm 0.6$

$133.3 \pm 0.3$

$116.6 \pm 1.0$

$125.9 \pm 1.0$

$102.9 \pm 2.5$

$102.6 \pm 0.5$

$126.3 \pm 1.0$

$63.6 \pm 1.4$

$49.2 \pm 0.2$

Priority Pollutants SRM 1586-2

Carbon tetrachloride- ${ }^{13} \mathrm{C}$

Beazene-d6

Chlorobenzene-ds

* Phenol-ds

Nitrobenzene- $d_{5}$

2-nitrophenol-d 4

2,4-dichlorophenol-d 3

Naphthalene-ds

Bis[2-ethylhexyl]phthalate-d4

Benzo(a)pyrene-d 12
123.5

98.7

143.5

115.9

134.0

102.3

82.4

126.5

60.2

43.8
$125.2 \pm 1.3$

$99.2 \pm 0.3$

$144.4 \pm 0.9$

$116.0 \pm 0.6$

$135.0 \pm 0.9$

$101.4 \pm 1.8$

$82.0 \pm 1.4$

$126.7 \pm 0.9$

$60.6 \pm 0.5$

$44.4 \pm 1.8$

"Uncertainties are given as $95 \%$ confidence intervals.

-Weighed as phenol-d6, but in methanol solution it converts quantitatively to phenol-ds. 
TABLE 3

Chemical Purity of Priority Pollutants in SRM 1586

\begin{tabular}{|c|c|c|}
\hline Determined by Gas & romatography & \\
\hline Compound & & Punty $\%$ \\
\hline SRM 1586-1 & & \\
\hline Carbon tetrachloride & & 99.9 \\
\hline Benzene & $\cdot$ & 99.9 \\
\hline Chlorobenzene & & 99.9 \\
\hline Phenol & & 99.9 \\
\hline Nitrobenzene & & 99.9 \\
\hline 2-nitrophenol & & 99.9 \\
\hline 2,4-dichlorophenol & & 99.9 \\
\hline Naphthalene & & 99.4 \\
\hline Bis[2-ethylhexyl]phthalate & & 99.5 \\
\hline Benzo(a)pyrene & & 99.5 \\
\hline SRM 1586-2 & & \\
\hline Carbon tetrachloride- ${ }^{13} \mathrm{C}$ & & 99.6 \\
\hline Benzene-d 6 & & 99.9 \\
\hline Chlorobenzene- $d_{5}$ & & 99.9 \\
\hline Phenol-d 6 & & 99.9 \\
\hline Nitrobenzene-ds & & 99.9 \\
\hline 2-nitrophenol-d4 & & 99.9 \\
\hline 2,4-dichlorophenol-d $d_{3}$ & & 98.4 \\
\hline Naphthalene-d8 & & 99.8 \\
\hline Bis $\left[2\right.$-ethylhexyl]phthalate- $d_{4}$ & & 96.7 \\
\hline Benzo(a)pyrene-diz & & 98.1 \\
\hline
\end{tabular}

TABLE 4

Isotopic Purity of Priority Pollutants in SR.M 1586-2

Determined by Mass Spectrometry

\begin{tabular}{|c|c|c|}
\hline Compound & Isotopic Purity, Percent & Totally Labeled \\
\hline Carbon tetrachloride- ${ }^{13} \mathrm{C}$ & 99.5 & 99.5 \\
\hline Benzene-d 6 & 99.7 & 97.9 \\
\hline Chlorobenzene-ds & 99.6 & 97.9 \\
\hline - Phenol-d6 & 98.3 (as $d_{5}$ ) & 91.4 (as $\left.d_{s}\right)$ \\
\hline Nitrobenzene-ds & 99.6 & 97.3 \\
\hline 2-nitrophenol-d $d_{4}$ & 98.9 & 95.5 \\
\hline 2,4-dichlorophenol-d 3 & 98.7 & 96.0 \\
\hline Naphthalene-ds & 99.5 & 95.6 \\
\hline Bis[2-ethylhexyl]phthalate-d 4 & 98.6 (aromatic ring only) & 94.5 (aromatic ring only) \\
\hline Benzo(a)pyrene-d 12 & 98.8 & 86.2 \\
\hline
\end{tabular}

Percent of Molecules

99.5

97.9

91.4 (as ds)

96.0

94.5 (aromatic ring only)

36.2 


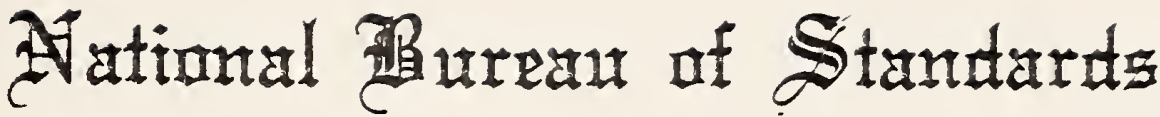

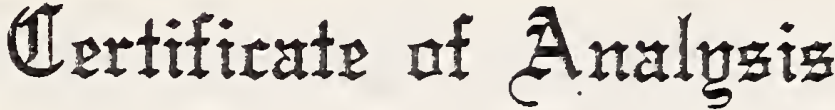

\section{Standard Reference Material 1614}

\author{
Dioxin $(2,3,7,8-T C D D$ in Isooctane)
}

Standard Reference Material (SRM) 1614 consists of separate solutions of uniabeled and labeled 2,3,7,8-tetrachlorodibenzo-p-dioxin (2,3,7,8-TCDD) in 2,2,4-trimethylpentane (isooctane). Three ampoules contain approximately $1.2 \mathrm{mI}$ each of an isooctane solution of unlabeied 2,3,7,8-TCDD, and three ampoules contain approximately $1.2 \mathrm{~mL}$ each of an isooctane solution of ${ }^{13} \mathrm{C}$-labeled 2,3,7,8-TCDD. This SRM is intended primarily for use in the evaluation of analytical methods used in the determination of 2,3,7,8:TCDD. It can also be used to fortify samples with known amounts of 2,3,7,8-TCDD. The ${ }^{13} \mathrm{C}$-labeled 2,3,7,8-TCDD can be used as an internal standard in methods based on gas chromatography/mass spectrometry (GC/MS).

\section{Certified Concentrations of 2,3,7,8-TCDD}

The certified concentrations and estimated uncertainties of the unlabeled and ${ }^{13}$ C-labeled $2,3,7,8-T C D D$ solutions are given in Table 1. The concentration values are certified in $\mathrm{ng} / \mathrm{g}$ units, but are also reported in $\mathrm{ng} / \mathrm{mL}$ units for user convenience. The ${ }^{13} \mathrm{C}$-labeled solution is certified for the total concentration of all isotopic forms of $2,3,7,8-T C D D$. The isotopic purity of the ${ }^{13} \mathrm{C}$-labeled material was determined to be $98.2 \pm 0.1$ atom percent ${ }^{13} \mathrm{C}$ by mass spectrometry. The fully ${ }^{13} \mathrm{C}$-labeled compound, 2,3,7,8-TCDD $-{ }^{13} \mathrm{C}_{12}$, accounts for $80.7 \pm 0.5$ percent of the $2,3,7,8-\mathrm{TCDD}$ molecules in the sample.

The certified values are the weighted averages of gravimetric values, based on the concentration calculated from the mass of 2,3,7,8-TCDD added to a known mass of isooctane and on the analytical results obtained using capillary gas chromatography with electron capture detection (GC/ECD). The uncertainties are two standard deviations of the certified values. These uncertainties include the gravimetric and $G C$ measurement variability and any observed material heterogeneity.

\section{NOTICE AND WARNING TO USERS}

Handling

The toxicity and/or carcinogenicity of 2,3,7,8-TCDD has not been precisely defined; however, this material should be treated as a potential health hazard. Ampoules should be opened and the contents used only by persons trained in proper handling techniques. Techniques used in handling radioactive and infectious materials are applicable to 2,3,7,8-TCDD. Users in the United States should contact their regional offices of the U.S. Environmental Protection Agency for information regarding proper disposal of these materials; in other countries, they should contact the appropriate organization responsible for public health or environmental control.

Trimethylpentane (isooctane), used as a diluent in this SRM, is stable when stored in closed containers at room temperature. It will not undergo hazardous polymerization. However, it is highly flammable and should be kept away from oxidizing agents.

Gaithersburg, MD 20899

July 8,1985
Stanley D. Rasberry, Chief Office of Standard Reference Materials

(over) 
Preparation and Analysis

Samples of the unlabeled 2,3,7,8-TCDD and ${ }^{13}$ C-2,3,7,8-TCDD used in the preparation of SRM 1614 were donated by R. Mitchum, National Center for Toxicological Research, Jefferson AK. The unlabeled 2,3,7,8-TCDD was originally obtained from ECO Control, Inc., Cambridge, MA; and the ${ }^{13}$ C-labeled 2,3,7,8-TCDD from Midwest Research Institute, Kansas City, MO. The purities of the labeled and unlabeled 2,3,7,8-TCDD used in the preparation of this SRM were determined at NBS using mass spectrometry, nuclear magnetic resonance spectrometry, and GC with name ionization derection. The purities were found to be greater than $95 \%$.

Solutions of the unlabeled 2,3,7,8-TCDD and the ${ }^{13}$ C-labeled $2,3,7,8-T C D D$ were prepared at NBS by weighing and mixing the appropriate compound and isooctane. Each solution was dispensed into 2-mL amber ampoules which were then flame sealed. Aliquots from randomly selected ampoules were analyzed with a gas chromatograph equipped for split injection and a $30 \mathrm{~m} \times 0.25 \mathrm{~mm}$ i.d. wall-coated open-tubular column with a $0.25 \mu \mathrm{m}$ film of a non-polar, immobilized phase. A constant current electron capture detector $\left({ }^{53} \mathrm{Ni}\right)$ was used for these analyses. Quantitative results were obtained through the use of $2,2^{\prime}, 4,4^{\prime}, 5,5^{\prime}$-hexachlorobiphenyl as an internal standard. Calibration solutions consisting of weighed amounts of the analyte and the internal standard compound in isooctane were analyzed chromatographically to determine response factors.

A trichlorodibenzo-p-dioxin impurity present in both solutions was quantified using GC/MS with electron impact ionization, selected ion monitoring, and the method of standard additions. Standard additions of unlabeled 2,3.7trichlorodibenzo-p-dioxin were made to the unlabeled and ${ }^{13} \mathrm{C}$-labeled 2,3,7,8-TCDD solutions, and although the retention time of the trichlorodibenzo-p-dioxin impurity was coincident with that of the 2,3,7-isomer, this was not sufficient to positively identify which isomer was present. Concentrations of the trichlorodibenzo-p-dioxin in the SR.M solutions are provided, for information only, in Table 2.

\section{Expiration of Certification}

This certification is valid within the specified limit of uncertainty for one year from the date of purchase. In the event that the certification should become invalid before then, purchasers will be notified by NBS.

\section{Storage}

Sealed ampoules, as received, should be stored in the dark at temperatures between 10 and $30^{\circ} \mathrm{C}$. It is recommended that these materials be stored in a secure area in a double-sealed container.

Use

Samples of the SRM should be withdrawn from ampoules (at $23 \pm 8^{\circ} \mathrm{C}$ ) immediately after opening and used without delay for the certified values listed in Table 1 to be valid within the stated uncertainties. Certified values are not applicable to material in ampoules stored after opening, even if they are resealed.

Preparation and analytical determinations were performed in the NBS Organic Analytical Research Division by S.N. Chesler, B. Coxon, L.R. Hilpert, R.M. Parris, R.E. Rebber, M.J. Welch, and E. White. V.

Consultation on the statistical design of the experimental work and evaluation of the data was provided by R.C. Paule of the NBS National Measurement Laboratory.

The coordination of the technical measurements leading to the certification of SRM 1614 was under the direction of L.R. Hilpert, R.M. Parris, and W.E. May.

The technical and support aspects involved in the preparation, certification, and issuance of this SR.M were coordinated through the Office of Standard Reference Materials by T.E. Gills.

SRM 1614

Page 2 
Table 1

Cerrified Concentrations of 2,3,7,8-TCDD ${ }^{2}$ in SRM 1614

Concentration ${ }^{\text {b }}$

Compound

2,3,7,8-TCDD

$2,3,7,8-\mathrm{TCDD}^{13} \mathrm{C}^{\mathrm{d}}$

$$
\underline{\mathrm{ng} / \mathrm{g}}
$$

$98.3 \pm 3.3$

$95.6 \pm 1.5$ $\mathrm{ng} / \mathrm{mL}^{6}, 23^{\circ} \mathrm{C}$

$67.8 \pm 2.3$

$65.9 \pm 1.0$

'CAS Registry Numbers: 2,3,7,8-TCDD ${ }^{12} \mathrm{C}_{12:}$ i746-01-6; 2,3,7,8-TCDD- ${ }^{13} \mathrm{C}_{12}$ : 76523-40-5, Chemical Abstracts, Tenth Collective Index. Index Guide, American Chemical Society, Columbus, Obio, 1982

'The uncerainties given represent two standard deviations of the cerified values. These uncertainties include the gravimetric and GC/ECD 2,3,7,8-TCDD measurement variability, the trichlorodibenzo-p-dioxin measurement variability, and, for the unlabeled 2,3,7,8-TCDD, the observed sample heterogeneity.

The concentration and uncertainty expressed in mass/volume units are applicable for use of this material at $23.0^{\circ} \mathrm{C}$. Since the density of 2,2,4-trimethylpentane changes with temperature, the concentration will change at temperatures other than $23.0^{\circ} \mathrm{C}$. The concentration will change by less than 1 percent of the value listed if the SRM is used at temperatures in the 15 to $31^{\circ} \mathrm{C}$ range.

'The concentrations given represent the total concentrations for all isotopic forms of 23,7,8-TCDD in the solution. The fully ${ }^{13}$ C-labeled $2,3,7,8-T C D D$ accounts for $80.7 \pm 0.5$ percent of the $2,3,7,2-T C D D$ molecules in the sample. This vaine is provided for information only.

Table 2

Concentrations of Trichlorodibenzo-p-dioxin in SRM 1614

Solution

Unlabeled Labeled $\left({ }^{13} \mathrm{C}\right)$

\section{Compound}

trichlorodibenzo-p-dioxin- ${ }_{13}^{12} \mathrm{C}_{12}$ trichlorodibenzo-p-dioxin- ${ }^{13} \mathrm{C}_{12}$
- Concentration ${ }^{2}$ $\underline{n g / g}$
ng/mL, $23^{\circ} \mathrm{C}$

Values not certified; provided for information only.

Page 3

SRM 1614 


\section{X゙litimal 解urraut of Standarts Urertifirate af Analyois}

\section{Standard Reference Material 1647}

\section{Priority Pollutant Polynuclear Aromatic Hydrocarbons (in Acetonitrile)}

This Standard Reference Material is intended for calibrating chromatograpnic instrumentation used in the determination of the polynuclear aromatic hydrocarbons ( $\mathrm{PAH}$ ') certified in this SRM. It is also useiul in recovery studies for adding known accurate amounts of these PAH's to a sample: and because of its miscibility with water, it can be used to fortify aqueous samples with known concentrations of PAH's.

Certified Concentrations of the PAH's:

The certified concentrations of the 16 organic constituents in acetonitrile are shown in Table 1 . Because the density of acet onitrile changes with temperature, these concentrations are cersified for the temperature range of 21 to $25^{\circ} \mathrm{C}$. Except for chrysene and dibenz[a.h]anthracene, each value is based on the concentration calculated from the mass of the PAH added to a known volume of the acetonitrile, on the analytical results obtained by high periormance liquid chromatography (HPLC), and for six compounds, also by gas chromatography (GC). The concentrations of chrysene and dibenz[a.h]anthracene, which did not dissolve completely, were certified based on the concordant results of the two independent methods, HPLC and GC, only. The calculated concentrations of the other 14 PAH's were corrected for compound purity determined by GC. Thirteen oi the 16 compounds added were at least $97.5 \%$ pure while theremaining three were at least $94 \%$ pure. Table 2 shows the calculated concentrations and the concentrations obtained by the analytical methods used in the certification.

\section{NOTICE AND WARNINGS TO USER}

Expiration of Certification: This certification is valid. within the limits certified, for one year from the date of purchase. In the event that the certification should become invalid before then. purchasers will be notified by NBS.

Storage: Sealed ampoules, as received, snould be stored in the dark at temperatures between $10-30{ }^{\circ} \mathrm{C}$.

Use: Samples of the SRM for analysis should be withdrawn from ampoules held at $23=2{ }^{\circ} \mathrm{C}$ immediately after opening and used without delay for any certified value in Table 1 to be valid within the staied uncertainty. Certilied values are not applicable to ampoules stored after opening, even if resealed.

Analytical determinations were performed at the Center for Analytical Chemistry. Organic Analyucal Research Division, by J.M. Brown-Thomas. F.R. Guenther. D.K. Hancock. and W.E. May.

Consultation on the statistical design of the experimental work was provided by K. R. Eberhardt of the Statustical Eng1neering Division.

The coordination of the technical measurements leading to certification were periormed under the directicn of W.E. May and H.S. Hertz.

The technical and support aspects involved in preparation. certification. and issuance of this Standard Reierence Material were coordinated through the Office of Standard Reference Materials by R. Alvarez.

Washington. D.C. 20234 


\section{PREPARATION AND ANALYSIS}

The acetonitrile solution of the 16 PAH's was prepared at Serco, Inc., Roseville, Minn. and ampouled cold into 5-mL amber glass ampoules. The ampoules were purged with nitrogen just prior to filling and sealed under nitrogen. Samples representing early, middle, and final stages of ampouling were analyzed by HPLC. No significant differences in concentration of the 16 compounds were found.

Randomly selected ampoules were analyzed for all 16 PAH's by HPLC on a Vydac ODS $(5 \mu \mathrm{m})$ column using an acetonitrile-water mobile phase. Four external standard solutions were used to provide quantitative data.

GC on a fused silica SE-54 capillary column was used to determine 8 of the 16 compounds. Two standard solutions were used to obtain compound responses relative to 1 -methylpyrene and m-tetrapheayl, the internal standards.

Ultraviolet absorption data between 205 and $600 \mathrm{~nm}$ are supplied as an aid in identifying each compound certified in this SRM. Table 3 gives the apparent specific molar absorbance for several promineat peaks in each spectrum. "Specific absorbance" is defined here as absorbance per unit pathlength and unit concentration. The term absorptivity was avoided because it is ambiguously defined (See Mielenz, K.D., Anal. Chem. 48, 1093-1094 (1976)). The term "apparent" is used because no corrections have been applied to the data for the effects of internal multiple renlections within the cuvette. The apparent molar specific absorbances were not corrected for PAH purity. Table 4 gives the apparent specific molar absorbances for each PAH at $254.0 \mathrm{~nm}$. The apparent specific molar absorbance at $254.0 \mathrm{~nm}$ should be used with caution. Because the absorbances measured at $254 \mathrm{~nm}$ do aot correspond to peak maxima, very small changes in wavelength may result in significant changes in the absorbance reading. The magnitude of this change is reflected in the last column of Table 4 which gives the percent change $\epsilon_{2}$ for a $1.0 \mathrm{~nm}$ shift away from $254.0 \mathrm{~nm}$. It is important that the user check the calibration of his instrument at $254 \mathrm{~nm}$.

Table 5 gives aqueous solubility values for 15 of the PAH's present in this SRM. These data, which are provided for information only, give an indication of how much of SRM 1647 can be added to a known volume of water without exceeding the aqueous solubilities of the PAH's. 
Table 1. Certified Concentrations of Polynuclear Aromatic Hydrocarbons in SRM 1647 at $23=2{ }^{\circ} \mathrm{C}$

Compound

Naphthalene

Acenaphthylene

Acenaphthene

Fluorene

Plienanthrene

Anthracene

Fluoranthene

Pyrene

Benz[a]anthracene

Chrysene

Benzo[b]fluoranthene

Benzo[k]fluoranthene

Benzo[a]pyrene

Benzo[ghi]perylene

Dibenz[a.h]anthracene

Indeno[1.2,3-cd]pyrene
Concentration. $4 \mathrm{~g} / \mathrm{mL}^{*}$

$22.5 \pm 0.2$

$19.1=.2$

$21.0=.4$

$4.92=.10$

$5.06=.10$

$3.29=.10$

$10.1=.2$

$9.84=.10$

$5.03=.10$

$4.68=.10$

$5.11=.10$

$5.02=.10$

$5.30=.10$

$4.01=.10$

$3.68=.10$

$4.06=.10$

*The estimated uncertainty given for each compound is based on judgment. and represents an evaluation of the combined effects of method imprecision. and possible systematic errors among methods.

Tabie 2. Summary of Results by the Analytical Methods Used in Cerrification

\begin{tabular}{|c|c|c|c|}
\hline \multirow[t]{2}{*}{ 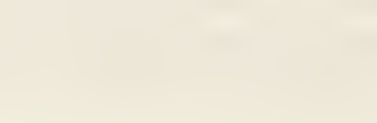 } & \multicolumn{3}{|c|}{ Concentration. $\mu \mathrm{g} \mathrm{mL}$} \\
\hline & Calculated & HPLC & $\mathrm{Gr}$ \\
\hline Naphthalene & 22.5 & $22.4 \pm 0.5^{4}$ & \\
\hline Acenaphthylene & 19.0 & $19.2=.5$ & \\
\hline Acenaphthene & 20.8 & $21.2=.4$ & \\
\hline Fluorene & 4.89 & $4.96=.18$ & \\
\hline Phenanthrene & 5.00 & $5.12=.18$ & \\
\hline Anthracene & 3.25 & $3.33=.10$ & \\
\hline Fluoranthene & 9.99 & $10.3=.5$ & \\
\hline Pyrene & 9.82 & $9.85=.58$ & \\
\hline Benz[a]anthracene & 4.99 & $5.12=.14$ & $\therefore .97=0.06$ \\
\hline Chrysene $^{b}$ & & $4.69=.15$ & $4.68=.06$ \\
\hline Benzo[b]fuoranthene & 5.11 & $5.13=21$ & $5.09=.06$ \\
\hline Benzo[k]Tiuoranthene & 5.00 & $5.06=.15$ & $4.99=.10$ \\
\hline Benzo[a]pyrene & 5.28 & $5.32=.13$ & $5.31=.19$ \\
\hline Benzo[ghi] perylene & 4.00 & $4.09=.30$ & $3.99=12$ \\
\hline Dibenz[a.h]anthracene ${ }^{h}$ & & $3.73=.12$ & $3.03=.07$ \\
\hline Indeno[1.2.3-cd]pyrene & 4.07 & $3.11=.15$ & $402=06$ \\
\hline
\end{tabular}

${ }^{2}$ Uncertainty is given as $95 \mathrm{c}^{\circ} \mathrm{c}$ contidence limits for the mean.

"Incomplete dissolution of compound. 
Tabie 3. Apparent Spesific Molar Absorbances at $\lambda_{\max }$

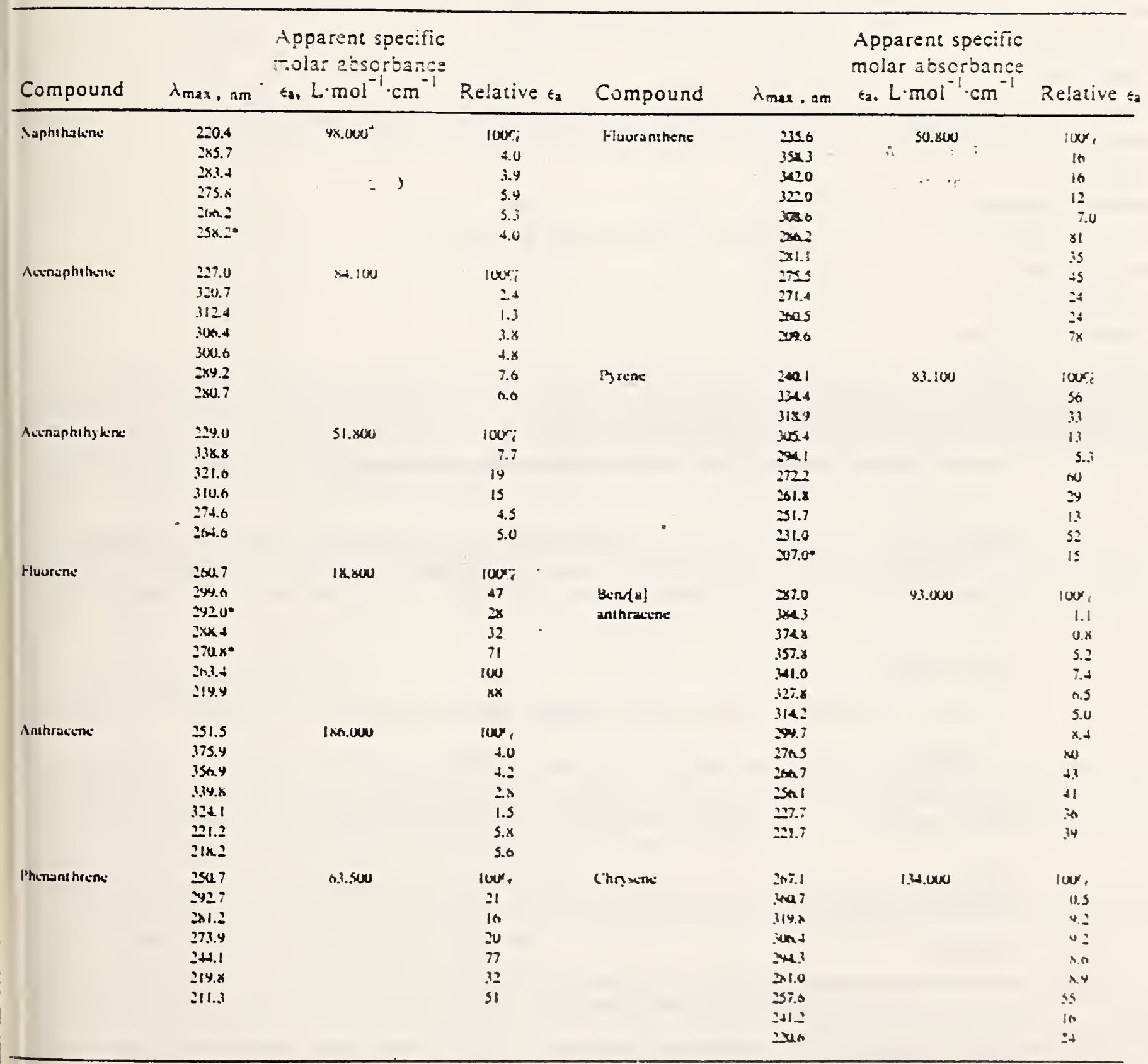

\section{'Shoulder}

These values are for information only and are not certilied. 
Table 4. Apparent Specilic Molar Absorbances at $254.0 \mathrm{~nm}$

\begin{tabular}{|c|c|c|c|}
\hline Compound & 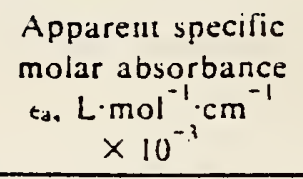 & $\begin{aligned} & \text { \% Relative } \\
= & \frac{t_{0.1} 254.0 \mathrm{~nm}}{t_{0 .} \cdot \lambda_{\text {mas }}} \times 100\end{aligned}$ & $\begin{array}{l}\text { e crror in } \\
\text { ed for } \\
\text { lnm error }\end{array}$ \\
\hline Naphthalene & 3.1 & $3.2 \%$ & $\| c \%$ \\
\hline Acenaphthene & 1.2 & 1.4 & 18 \\
\hline Acenaphthylene & 2.2 & 4.1 & 2 \\
\hline Fluorene & 17 & $\cdot 88$ & 1 \\
\hline Anihracene & 96 & 52 & 52 \\
\hline Phenanchrene & 43 & 68 & 16 \\
\hline Fluoranthene & 13 & 25 & 6 \\
\hline Pyrene & 10 & 12 & 5 \\
\hline Benz[a]anthracene & 33 & 36 & 3 \\
\hline Chrysene & 52 & 39 & 15 \\
\hline Benzo[b]lluoranthene & 43 & 96 & 4 \\
\hline Benzo[k]lluoranthene & 28 & 48 & 15 \\
\hline Benzo[a]pyrene & 42 & 72 & 2 \\
\hline Benzolghi]perylene & 16 & 27 & 0.7 \\
\hline Dibenda.h]anthracene & 11 & 7 & 6 \\
\hline Indeno[ $1.2,3-c d]$ pyrene & 38 & 53 & 22 \\
\hline
\end{tabular}

The values in this table are for information only and are not certified.

Table 5. Aqueous Solubility Data for the Individual PAH Compounds Present in SRM 1647

Cómpound

Naphthalene

Acenaphthylene

Acenaphthene

Fluorene

Phenanthrene

Anthracene

Fluoranthene

Pyrene

Benz[a]anthracene

Chrysene

Benzo[b]nuoranthene

Benzo[k]nuoranthene

Benzo[a]pyrene

Benzo[ghi]perylene

Dibenz[a,h]anthracene

Indeno 1 1.2,3-cd]pyrene
Aqueous Solubility at $25^{\circ} \mathrm{C}$.

$(\mathrm{ng} / \mathrm{mL}$ )

$(31700)^{4}$

$(3930)^{b}$

(1685)

$(1000)$

(206)

(132)

These sislus are supplicd lor inlormation and are not cerrilied. Thisy are provided tur user who wish to add this acetonatrile solution to water lor recuicry studin. Sote that the salubilities are lor individual PAH', and may change in an syucivas wilution of the in l'AH's.

"U. Mackdy and W. Shiu. J. Chem. Ent Dalx. 22, +(1477).

"W. Davis. M. Krahl and C. Cluwes. J. Am. Chem. suc. ㅆ. 108-141/4421.

All uther solubility values were determined at NBS using Dynamic Coupled Column Layurd Chromatographic Techniuue. 


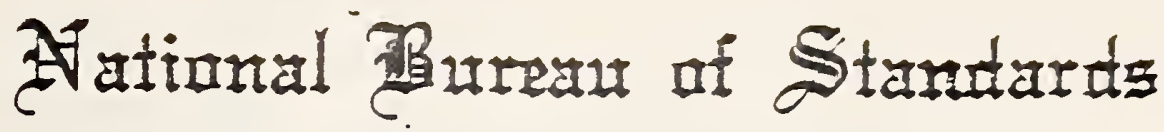

\section{Uertifitate}

\section{Standard Reference Material 1643b}

\author{
Trace Elements in Water
}

This Standard Reference Material (SRM) is intended primarily for use in evaluating the aceuracy of trace element determinations in filtered and acidified fresh water and for calibrating instrumentation used in these determinations. SRM $1643 \mathrm{~b}$ consists of approximately $950 \mathrm{~mL}$ of water in a polyethyleze bottle, which is sealed in an aluminized bag:0 maintain stability. SRM $1643 \mathrm{~b}$ simulates the elemental composition of fresh water. Nitric acid is present at a concentration of 0.5 moles per liter to stabilize the trace elements.

Concentrations of Constituent Elements: The concentrations of the trace elements that were determined are shown in Table 1 . The certified values are based on results obtained either by reierence methods of known aceuracy or by :wo or more independent, reliable analytical methods. Noncertiried values, which are given for infomation only, apoear in parentheses.

Notice and Warnings to Users:

Expiration of Cerrification: This certification is invalid two years after the shipping date.

Precautions: The bottle should be shaken before use because of possible water vapor condensation. To prevent possiole contamination of the SRM, do not insert pipets into the bottle. After use, the bottle should be capped tightly and placed inside the aluminized bag, which should be folded and sealed with sealing tape. This safeguard will protect the SR.M from possible environmental contamination and long-term loss of water.

Elemental determinations of $\mathrm{ng} / \mathrm{g}$ levels are limited by contamination. Apparatus should be scrupulously cleaned and only the purest grade reagents employed. Sampling and manipulations, such as evaporations, should be done in a clean environment, for example, a Class 100 clean hood.

The overall direction and coordination of the technical measurements leading to this cerification were periormed under the direction of E. Garner, Chief of the Inorganic Analytical Research Division.

The technical and support aspects involved in the preparation, certification. and issuance of this Standard Reference Material were coordinated through the Office of Standard Reference Materials by R. Alvarez

Washington, DC 20234

May 18,1984
Stanley D. Rasberry. Chief Office of Standard Reference Materiais 
(Table 1)

Concentrations of Constituent Elements

\begin{tabular}{|c|c|c|c|}
\hline Element & $\begin{array}{c}\text { Concentration. } \\
\mathrm{ng} / \mathrm{g} \\
\end{array}$ & Element & $\begin{array}{c}\text { Concentration, } \\
\mathrm{ng} / \mathrm{g}\end{array}$ \\
\hline Arsenic ${ }^{1.5}$ & $(49)^{*+}$ & $\operatorname{Lead}^{3+4 b}$ & $23.7=0.7$ \\
\hline Barium $^{23.2 b .5}$ & $44 \pm 2$ & Manganese $^{1, \mathbf{2} .3}$ & $28 \pm 2$ \\
\hline Beryilium $^{l, 2 \mathbf{a}}$ & $19 \pm 2$ & Molybdenum $^{23.5}$ & $85 \doteq 3$ \\
\hline Bismurh $^{\prime}$ & (1!) & Nickel $^{2.3}$ & $49=3$ \\
\hline Boron $^{23}$ & (94) & Selenium $^{1.5}$ & $9.7=0.5$ \\
\hline Cadmium $2 b .3 .5$ & $20 \pm 1$ & Silver ${ }^{1.5}$ & $9.8=0.8$ \\
\hline Chromium $^{\text {sb }}$ & $18.6 \pm 0.4$ & Strontium & $227 \pm 6$ \\
\hline Cobalt ${ }^{1.5}$ & $26=1$ & Thallium ${ }^{4 b}$ & $8.0=0.2$ \\
\hline Copper ${ }^{3.4 b}$ & $21.9 \pm 0.4$ & Vanadium ${ }^{4 b}$ & $45.2=0.4$ \\
\hline Iron 2.4 .5 & $99 \pm 3$ & Zinc ${ }^{22.5}$ & $66 \pm 2$ \\
\hline
\end{tabular}

- The estimated uncerainty is based on judgment and represents an evaluation of the combined effects of method imprectsion and possible systematic errors amung methods. To conver to nanograms per milliliter. multiply by the density of the $S R . M$. The density at $23^{\circ} \mathrm{C}$ is 1.019 grams per milliliter.

- Values in parentheses are not cerrified.

1. Atomic absorption spectrometry, electrothermal

2 Atomic emission spectrometry.
a. de piasma
b. flame

3. Laser enhanced ionization flame spectrometry

4. Isotopic dilution mass spectrometry.

2. resonance ionizauon

b. : inermal ionization

5. Neutron activation instrumental

Source and Preparation of Material: SR.M 1643b was prepared at the U.S. Geological Survey, Vational Water Quality Laboratory, Arvada. Colorado, under the direction of V.J. Janzer of that laboratory and J.R. Moody of the NBS Center for Analytical Chemistry. Only high-purity reagents were used and the containers were acid-cleaned and sterilized before use. In the preparation, a polyethylene cylindrical tank was filled with distilled water and sufficient nitric acid to make the solution approximately 0.5 moles $\mathrm{HNO}_{3}$ per liter. Solutions containing known amounts of calcium. sodium. magnesium, potassium, and the elements to be determined were added to the acidified water solution with constant stirring. After thoroughly mixing, the solution was filtered, sterilized, and then transierred to one-liter polyethylene bottles. The approximate concentrations, in $\mu \mathrm{g} / \mathrm{mL}$, of $\mathrm{Ca} . \mathrm{Na}, \mathrm{Mg}$, and $\mathrm{X}$ are respectively $35,3,15$, and 3 .

Analysts:

Center fo- Analytical Chemistry, National Bureau of Standards

1. K. A. Brletic

10. J. R. Moody

2. T. A. Butler

11. L. J. Powell

3. E. C. Deal

12. T. C. Rains

4. M. S. Epstein

13. T. A. Rush

5. J. D. Fassett

14. S. F. Stone

6. K. Fitzpatrick

15. G. C. Turk

7. H. M. Kingston

16. R. L. Watters, Jr.

8. R. M. Lindstrom

17. R. Zeisler

9. L. A. Machlan 


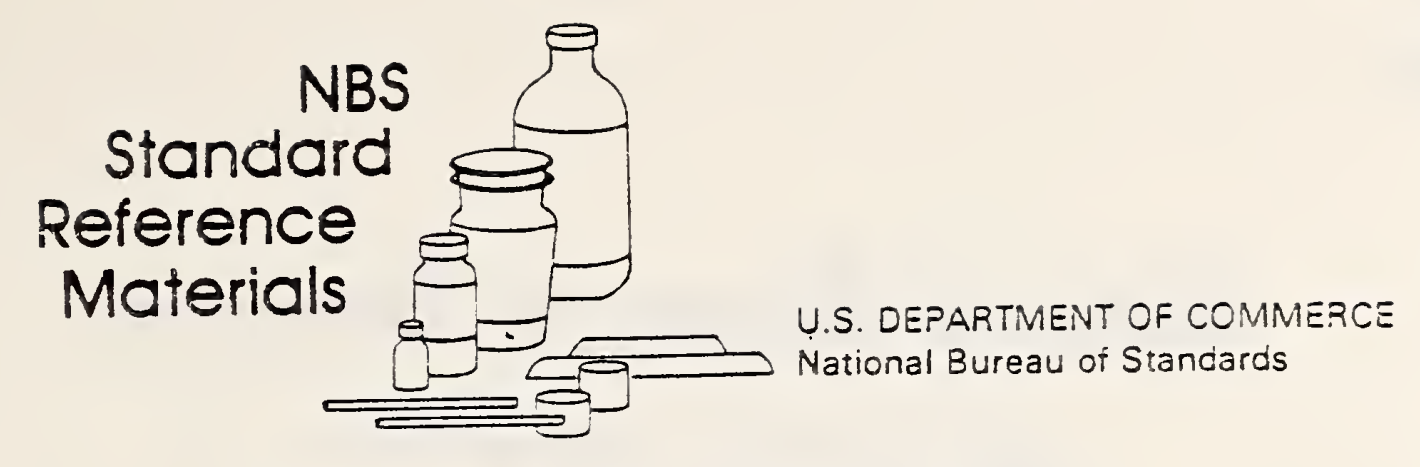

Standard Reference Material 2121-2129

Spectrometric Standard Solutions

Spring 1995

The NBS Office of Standard Reference Materials has available aqueous spectrometric solution Standard Reference Materials (SRM's). They are intended for use in atomic absorption spectrometry, optical emission (plasma) spectrometry, spectrophotometry, or any other analytical technique that requires aqueous solutions for calibration.

These SRM's, listed below, are prepared from NBS-SRM's or well-characterized high-purity metals or salts using NBS high-purity acids. Most solutions are prepared gravimetrically to contain $10.00 \mathrm{mg} / \mathrm{mL}$ of the selected metal in a 10 percent acid medium. For SRM 2121, the volume of each solution is $35 \mathrm{~mL}$ : for the other SRM's the volume of each solution is $50 \mathrm{~mL}$.

SRM's 2121 through 2126 are now available; the others are planned to be issued at two month intervals until the series has been completed. Each of the SRM's consists of four single-element solutions, contained in individual bottles.

$\underline{\text { SRM }}$ Metals

2121 Cadmium, Lead, Silver, and Zinc

2122 Barium, Calcium, Magnesium, and Strontium

2123 Lithium, Potassium, Sodium, and Rubidium

2124 Cobalt, Copper, Iron, and Nickel

2125 Boron, Chromium, Manganese, and Molybdenum

2126 Antimony, Arsenic, Selenium, and Tin

2127 Aluminum, Beryllium, Phosphorus, and Silicon

2128 Gold, Mercury, Palladium, and Platinum

2129 Titanium, Tungsten, Vanadium, and Zirconium

The first six of these SRM's are now available for $\$ 160$ per unit from:

Office of Standard Reference Materials

Room B311, Chemistry Building

National Bureau of Standards

Gaithersburg, MD 20899

Telephone: $301-921-2045$ 


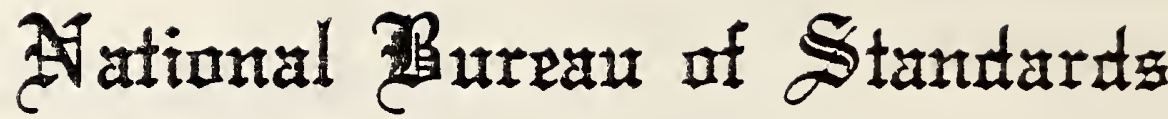

\author{
UTertifirate of Analygis
}

\section{Standard Reference Material 1646}

\author{
Estuarine Sediment
}

This Standard Reference Material is intended primarily for calibrating instrumentation and evaluating the reliability of analytical methods for the determination of major, minor, and trace elements in sediments, and similar matrices.

Values of Constituent Elements: The certified values for the constituent elements are shown in Table I. They are based on results obtained either by definitive methods or by two or more independent, reliable analytical methods. Noncertified values, which are given for information only, appear in Table 2 . All values are based on a minimum sample size of $500 \mathrm{mg}$ of the material dried as indicated under "Instructions for Drying".

\section{Notice to Users:}

Expiration of Certification: The certification of this SRM will be invalid 5 years after date of shipping.

Use: The material should be kept in its original bottle and shaken well before each use. A minimum sample of $500 \mathrm{mg}$ of the dried material (see Instructions for Drying) should be used for any a nalytical determination to be related to a certified value of this certificate.

Statistical consultation was provided by K. R. Eberhardt of the Statistical Engineering Division.

The overall direction and coordination of the technical measurements leading to certification were performed in the Inorganic Analytical Research Division, E. L. Garner, Chief.

The technical and support aspects involved in the preparation, certification, and issuance of this Standard Reference Material were coordinated through the Office of Standard Reference Materials by R. Alvarez.

Washington. D.C. 20234

June 7,1982

(Revision of Certificate

dated 1-6-82) 
Table 1. Certified Concentration of Constituent Elements

\section{Element}

Aluminum $2 b, c ; n$

Calcium ${ }^{2 b, \because ; b}$

Iron $2:$ :idich .

Element

Arsenic $^{14 ; t h}$

Cadmium ${ }^{1 b, 3 a, b ; t h}$

Chromium ${ }^{10} ; 3 b_{;}$ta

Cobalt ${ }^{\text {h } ; \text { id }}$

Copper ${ }^{10 ;} ; 2 ;$ th

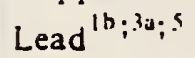

\section{Concentration,} weight \%

$6.25 \pm 0.20$

$0.83 \pm 0.03$

$3.35=0.10$

Concentration, $\mu \mathrm{g} / \mathrm{g}$

$$
\begin{aligned}
11.6 & \pm 1.3 \\
0.36 & \pm 0.07 \\
76 & \pm 3 \\
10.5 & \pm 1.3 \\
18 & \pm 3 \\
28.2 & \pm 1.8
\end{aligned}
$$

Concentration,

weight \%

Element

Magnesium $^{1 e ; 2 c}$

Phosphorus ${ }^{2 a} ;$

$1.09 \pm 0.08$

$0.054 \pm 0.005$

Concentration,

Element

Manganese $^{1 c ; 2 \varepsilon}$

Mercury ${ }^{1 a ; 4 b}$

Nickel $^{1 b ; 2 c ; 5}$

Vanadium $^{2 a, 3 i x}$

Zinc $^{1 b, c ; 2 c ; 3 b ; 5}$ $\mu \mathrm{g} / \mathrm{g}$

$375 \pm 20$

$0.063 \pm 0.012$

$32 \pm 3$

$94 \pm 1$

$138 \pm 6$

1. Atomic absorption spectrometry
a. cold vapor
b. graphite furnace
c. name
d. hydride generation

3. Isotope dilution mass spectrometry

a. thermal ionization

b. spark source

4. Neutron activation
a. instrumental
b. radiochemical

5. Polarography

6. X-ray fluorescence spectrometry
i. dc plasma
b. tlame
c. inductively coupled plasma

Notes: (1.) Analytical values are based on the "dry-weight" of material (see Instructions for Drying). Mercury should be determined on samples without drying and the results adjusted to a "dry-weight" basis by determining the moisture content of separate samples.

(2.) The estimated uncertainty for an element is based on judgment and represents an evaluation of the combined effects of method imprecision. possible systematic errors among methods. and material variability for samples $500 \mathrm{mg}$ or more. 
Note: The values shown in this table are not certified because they are not based on the results of either a derinitive method or two or more independent analytical methods. These values are included, for information only, to provide additional information on the composition.

\begin{tabular}{|c|c|c|c|}
\hline Element & $\begin{array}{c}\text { Concentration, } \\
\text { Weight } \% \\
\end{array}$ & Element & $\begin{array}{l}\text { Concentration. } \\
\text { Weight \% }\end{array}$ \\
\hline Potassium & (1.4) & Sulfur & $(0.96)$ \\
\hline Silicon & (31) & Titanium & $(0.51)$ \\
\hline Sodium & $(2.0)$ & & \\
\hline Elcment & $\begin{array}{c}\text { Concentration, } \\
\mu \mathrm{g} / \mathrm{g} \\
\end{array}$ & Element & $\begin{array}{c}\text { Concentration, } \\
\mu \mathrm{g} / \mathrm{g} \\
\end{array}$ \\
\hline Antimony & $(0.4)$ & Molybdenum & $(2.0)$ \\
\hline Beryilium & (1.5) & Rubidium & $(87)$ \\
\hline Cerium & $(80)$ & Scandium & $(10.8)$ \\
\hline Cesium & $(3.7)$ & Selenium & $(0.6)$ \\
\hline Europium & (1.5) & Te!lurium & $(0.5)$ \\
\hline Germanium & $(1.4)$ & Thallium & $(0.5)$ \\
\hline Lithium & (49) & Thorium & $(10)$ \\
\hline
\end{tabular}

Analysts:

Inorganic Analyucal Research Division, National Bureau of Standards. 1. L. Barnes, M. B. Blackburn, C. G. Blundell. T. A. Butler, M. S. Epstein. T. E. Gilis, J. W. Gramlich, R. R. Greenberz. S. Hanamura, W. R. Kelly, H. M. Kingston. L. Machlan, E. J. Maienthal, J. D. Messman, T. J. Murphy, T. C. Rains, T. A. Rush, R. Sedivy, and R. L. Watters. Jr.

Cooperating Analysts:

University of Tokyo, Tokyo, Japan; present address: Meteorological Research lnstitute; Tsukuba, Ibaraki. Japan: Y. Dokiya (NBS Guest Worker).

Division of Chemistry. National Researeh Council of Canada, Ottawa, Canada; S. Berman, A. Desaulniers, R. Sturgeon, A. Mykytuik, J. McLaren, V. Boyko, and P. Semeniuk.

Instructions for Drving. Except for mercury, elements should be determined on samples that have been dried at $110^{\circ} \mathrm{C}$ for 2 hours.

Mercury should be determined on undried samples. However, because the cerified concentration is reporied on a-dryweight basis, the concentration determined on undried samples should be adjusted for the moisture content of the samples.

Source and Preparation of Material: The material for this SR.M was supplied by R. Huggett. Virginia Insinuse of . Marine Sciences, Gloucester Point, Va It had been dredged from the Chesapeake Bay at a location: $37^{\circ} 11.1^{\circ} \mathrm{V}$. $76^{\circ} 17.1^{\circ} \mathrm{W}$. The material was freeze-dried at Eastern Freeze-Dry Corporation. Lancaster. Pa.. and radiation sterilized at Neutron Products Inc.. Dickerson. Md. At NBS, the sediment was sieved through a screen with openings of $1.00 \mathrm{~mm}$ (No. 18 ) to remove coarse contaminants; ball-milled to pass a sieve with openings of $150 \mu \mathrm{m}$ (No. 100); thorougnly mixed in a V-blender, placed in polyethylene bags; and bottled.

Homogeneity Assessment: A preliminary evaluation of bomogeneity was made by instrumenual neutron acuivation using samples of approximately $250 \mathrm{mg}$ taken from various locations of the bulk materiais. The samples were irradiated and the aciivities from radionuclides of Ce. Co, Cr, Cs, Eu. Fe, Rb, Sc and Th were counted. Except for Ce and Th. the observed sample-to-sample variations for the elements were approximately the same as the counting statisucs indicating satisfactory homogeneity for these elements within approximately $2 \%$. The homogeneity of the material for As. Cd. $\mathrm{Hg}$. $\mathrm{N}$, and $\mathrm{Zn}_{\mathrm{n}}$ was evaluated by various analytical techniques using samples weighting $25010300 \mathrm{mg}$ and found to be satisfactory. The homogeneity of the remaining cerinied elements was determined using sample weights not exceeding one gram.

The uncertainties of the elemental concentrations in Tabie I take into account possible material inhomogeneity lor samples weighing $500 \mathrm{mg}$. 
APPENDIX D

NOAA/NBS Methods Development/Quality Assurance Workshop

Attendees

Dr. Elliot Atlas

$(409 / 845-2986)$

Dept. of Oceanography

Texas A\&M University

College Station, TX 77843

Dr. Robert Barrick

$(206 / 822-9596)$

Sr. Chemist

Tetra Tech

11820 NE Northup Way

Suite 100

Bellevue, WA 98005

Mr. Donald Becker

React B108

$(301 / 921-2166)$

National Bureau of Standards

Gaithersburg, MD 20899

Dr. Shier S. Berman

$(613 / 993-2830)$

Division of Chemistry

National Research Council

Ottawa K1A OR6

CANADA

Dr. John A. Calder

NOAA/NOS/OOMA

N/OMA 32

Rockville, MD 20852

Dr. Stephen Chesler

222/A113

National Bureau of Standards

Gaithersburg, MD 20899

Dr. Robert C. Clark, Jr.

$(206 / 442-5596)$

NOAA/NMFS F/NWC6

2725 Montlake Boulevard East

Seattle, WA 98112

Dr. Adriana Cantillo

NOAA/NOS/OOMA

$(301 / 443-8655)$

N/OMA32

Rockville, MD 20852

$(301 / 443-8655)$ 


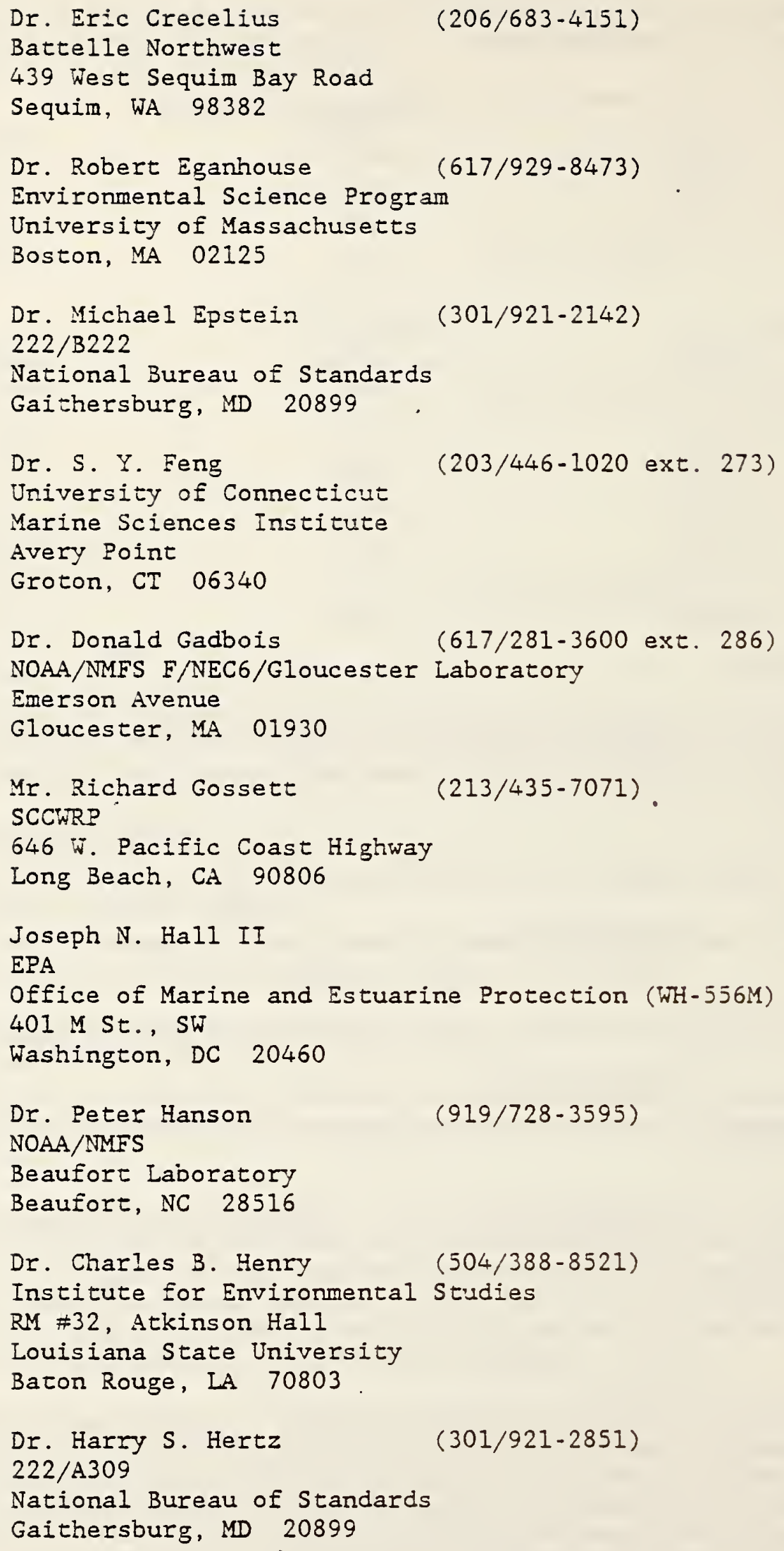


Dr. David Kalman

$(206 / 543-4252)$

School of Public Health and Community Medicine University of Washington

Seattle, WA 98195

Mr. Gunnar Lauenstein

$(301 / 443-8655)$

NOAA/NOS/OOMA

N/OMA 32

Rockville, MD 20852

Dr. William MacLeod

$(206 / 442-4240)$

NOAA/NMFS F/NWC6

2725 Montlake Boulevard, East

Seattle, WA 98112

Dr. Willie E. May

$(301 / 921-3778)$

222/A113

National Bureau of Standards

Gaithersburg, MD 20899

Ms. Reenie Parris

$222 /$ A113

$(301 / 921-2153)$

National Bureau of Standards

Gaithersburg, MD 20899

Dr. Robert Paule

223/A361

$(301 / 921-2305)$

National Bureau of Standards

Gaithersburg, MD 20899

Dr. James R. Payne

Science Applications International

476 Prospect Street

La Jolla, CA 92037

Dr. Donald Phelps

$(401 / 789-1071)$

Environmental Research Laboratory

USEPA

South Ferry Road

Narragansett, RI 02882

Dr. Richard H. Pierce

Mote Marine Laboratory

1600 City Island Park

Sarasota, FL 33577

Dr. Bob J. Presley

Department of Oceanography

$(409 / 845-5136)$

Texas A\&M University

College Station, TX 77843 
Mr. Ted Rains

$222 / B 222$

National Bureau of Standards

Gaithersburg, MD 20899

Dr. Stanley D. Rice

NOAA/NMFS/NWAFC

Box 155

Auke Bay, AK 99821

Dr. James Sanders

Director

Benedict Estaurine Research Laboratory

Benedict, MD 20612

Dr. Michelle (Miller) Schantz (301/921-2153)

222/A113

National Bureau of Standards

Gaithersburg, MD 20899

Dr. Robert Shokes

$(619 / 456-7506)$

Science Applications International Corp.

476 Prospect Street

LaJolla, CA 92038

Dr. Jeff Short

$(907 / 789-7231)$

NOAA/NMFS/NWAFC

Box 155

Auke Bay, AK 99821

Dr. Robert B. Spies

$(415 / 422-5792)$

Lawrence Livermore National Laboratory

P.O. Box $5507, \mathrm{~L}-453$

Livermore, CA 94550

William G. Steinhauer

Battelle New England Marine Laboratory

397 Washington Street

Duxbury, MA 02332

Dr. John Taylor

$(301 / 921-3497)$

222/A309

National Bureau of Standaris

Gaithersburg, MD 20899

Dr. Terry Wade

Department of Oceanography

$(409 / 845-3872)$

Texas Adx University

College Station, TX 77843 
Dr. John Wells

NOAA/NMFS F/SEC8

P.O. Box 12607

Charleston, SC 29412

Dr. Stephen A. Wise

222/A113

National Bureau of Standards

Gaithersourg, MD 20899

Dr. David Young

NOAA/NOS/OOMA

N/OMA32

Rockville, MD 20852

Mr. Vincent S. Zdanowicz

NOAA/NMFS E/NEC4

Sandy Hook Laboratory

Highlands, NJ 07732

Dr. Rolf Ziesler

React $B 108$

National Bureau of Standards

Gaithersburg, MD 20899
(803/762-1200 Comm)

(677-4773 FTS)

$(301 / 921-2154)$

$(301 / 443-8655)$

$(301 / 921-2166)$ 
N8S-114A (REV. 2-8C)

U.S. DEPT. OF COMM.

1. PUBLICATION OR

2. Performing Organ. Report Nof 3. Publication Date

BIBLIOGRAPHIC DATA

SHEET (See in structions)

4. TITLE ANO SUBTITLE

Summary Report of NOAA-NBS Quality Assurance Workshop

5. AUTHOR(S)

6. PERFORMING ORGANIZATION (If joint or other thon NBS, see instructions)

NATIONAL BUREAU OF STANDARDS

DEPARTMENT OF COMMERCE

WASHINGTON, D.C. 20234

9. SPONSORING ORGANIZATION NAME AND COMPLETE ADDRESS (Street. City, State, ZIP)

National Oceanic and Atmospheric Administration

National Ocean Service

Office of Oceanography and Marine Assessment

Rockville, MD 20852

10. SUPPLEMENTARY NOTES

Document describes a computer program: SF-185, FIPS Software Summary, is attached.

11. ABSTRACT (A 200-word or less factual summary of most significant information. If document includes a significone bibliography or literature survey. mention it here)

This report summarizes the proceedings of a methods development, quality assurance workshop held at the National Bureau of Standards, December 5-6, 1985, as part of NOAA's continuing effort to improve the quality of marine monitoring data. The workshop consisted of a series of contributed papers and group discussions of the results of collaborative measurements of a group of test samples. Summaries of the papers and the group discussions are included in this report.

12. KEY WOROS (Six to twelve entries; olphabetical order; copitolize only proper nomes; ond seporate key words by semicolons) Analytical chemistry; collaborative tests; data quality; marine monitoring dat3; methods development; quality assurance

13. AVAILABILITY

$\square$ Unlimited

[7] For Official Distribution. Do Not Release to NTIS

$\square$ Order From Superintendent of Documents, U.S. Government Printing Office, Washington. O.C. 20402.

$\square$ Order From National Technical Information Service (NTIS). Springfield, VA. 22161
14. NO. OF

PRINTED PAGES

68

15. Price

$\$ 11.95$ 

